\author{
Universidade de SÃo Paulo \\ Instituto de Física de SÃo CARLOS \\ Departamento de FísicA E InFormática
}

\title{
Uma Ferramenta Orientada ao Objeto para Monitoramento de Cargas em Sistemas Paralelos
}

Paulino Ribeiro Villas Boas

\author{
Dissertação apresentada ao Instituto \\ de Física de São Carlos - IFSC, USP, \\ como parte dos requisitos necessários \\ para obtenção do título de Mestre em \\ "Física Aplicada - Opção Física \\ Computacional"
}

Orientador: Prof. Dr. Gonzalo Travieso

SÃo CARLOS 2004 
Aos meus pais, Laércio e Terezinha. 


\section{Agradecimentos}

A Deus, pela oportunidade de realização de mais um passo importante na minha vida.

À minha família, por todo o amor, carinho, compreensão e incentivo. Especialmente, aos meus pais Laércio e Terezinha, pelas lições de vida e pela formação.

Aos meus amigos, que sempre me apoiaram e acreditaram na realização deste trabalho.

Aos meus amigos do grupo, o Francisco, a Thaty, o André, a Elô e o Zem, pelo companheirismo e pela ajuda sempre prestativa.

Ao Prof. Dr. Gonzalo, pela amizade, confiança, paciência, otimismo, e pela grande competência na orientação do trabalho.

A todas as pessoas que colaboraram direta ou indiretamente para a realização deste trabalho.

À CAPES, pelo apoio financeiro. 
1 Introdução 1

1.1 Organização da dissertação . . . . . . . . . . . . . . . 4

2 Computação Paralela $\quad 6$

2.1 Arquitetura de computadores paralelos . . . . . . . . . 7

2.2 Programação paralela . . . . . . . . . . . . . . . . . . 11

2.3 Ferramentas e linguagens para programação paralela . . . . . . . 12

2.3.1 Bibliotecas de comunicação entre processos . . . . . . . . 12

2.3.2 Compiladores paralelizantes . . . . . . . . . . 13

2.3.3 Linguagens de paralelismo implícito . . . . . . . . . . 14

2.3.4 Linguagens de paralelismo explícito . . . . . . . . 15

2.3.5 Sistemas voltados a área específica . . . . . . . . . 16

2.4 Medidas de desempenho de algoritmos paralelos . . . . . . . 17

2.5 Resumo do Capítulo . . . . . . . . . . . . . . . . . . 18

3 Balanceamento de Cargas 19

3.1 Considerações iniciais . . . . . . . . . . . . . . . 19

3.2 Políticas para o compartilhamento de cargas . . . . . . . . . 21

3.2.1 Propriedades desejáveis para as políticas . . . . . . . 22

3.2.2 Medidas de carga computacional . . . . . . . . . . 22 
3.2.3 Componentes das políticas . . . . . . . . . . 23

3.2.4 Estabilidade e eficiência . . . . . . . . . . . 25

3.2 .5 Classificação . . . . . . . . . . . . . 26

3.2.6 Exemplos de algoritmos de distribuição de cargas . . . . . 29

3.3 Resumo do capítulo . . . . . . . . . . . . . . 33

4 Sistema de Monitoramento de Cargas 35

4.1 Considerações iniciais . . . . . . . . . . . . . . 35

4.2 Ferramentas utilizadas . . . . . . . . . . . . . 37

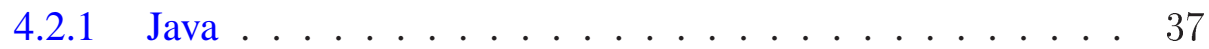

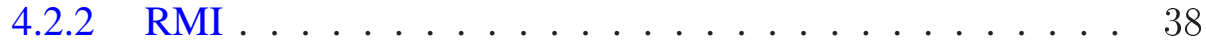

4.2.3 Sistema utilizado para desenvolvimento e teste . . . . . . 40

4.3 Descrição do sistema de monitoramento . . . . . . . . . . . . . . 41

4.3.1 Interface LoadIndex . . . . . . . . . . . . . . . 42

4.3 .2 Interface Resource . . . . . . . . . . . . . 44

4.3.3 Servidores e clientes . . . . . . . . . . . . . 48

4.3.4 Inclusão de novos tipos de medidas . . . . . . . . . 50

4.4 Resumo do capítulo . . . . . . . . . . . . . . . . . . . . 51

5 Testes e resultados

5.1 Considerações iniciais . . . . . . . . . . . . . . . 52

5.2 Problema abordado . . . . . . . . . . . . . 53

5.3 Solução seqüencial . . . . . . . . . . . . . . . 5 55

5.4 Solução paralela . . . . . . . . . . . . . . . 56

5.4.1 Compartilhamento estático de cargas . . . . . . . . 57

5.4.2 Compartilhamento dinâmico de cargas . . . . . . . . . 57

5.5 Resultados ........................ 60

5.5.1 Primeiro teste: tabuleiro de $5 \times 5 \ldots \ldots 60$ 
5.5.2 Segundo teste: tabuleiro de $5 \times 6 \ldots \ldots$. . . . . 66

5.6 Resumo do capítulo . . . . . . . . . . . . . . . . . . . . . . . . 69

6 Conclusões e Trabalhos Futuros 71

6.1 Conclusões . . . . . . . . . . . . . . . . . . 71

6.2 Trabalhos Futuros . . . . . . . . . . . . . . . . . . 73 


\section{Lista de Figuras}

2.1 Taxionomia para máquinas paralelas. Fonte [1]. . . . . . . . . . 8

3.1 Classificação da distribuição de cargas. . . . . . . . . . . . . . . 26

4.1 Diagrama mostrando a separação entre interface e implementação Fonte $[2] . \ldots \ldots \ldots$

4.2 Diagrama mostrando a distinção entre proxy e implementação do serviço. Fonte [2]. . . . . . . . . . . . . . . . . . 40

4.3 Cluster de computadores do Laboratório de Processamento Paralelo Aplicado, utilizado para desenvolver e testar o sistema de monitoramento de cargas. . . . . . . . . . . . . . . . . . . 41

4.4 Esquema mostrando como funciona o sistema de monitoramento de cargas. . . . . . . . . . . . . . . . . . . 42

4.5 Trecho que mostra o início do arquivo /proc/stat. . . . . . . . 45

4.6 Trecho do arquivo / proc/meminfo que mostra a quantidade total e usada de memória RAM (no arquivo, Mem é a memória RAM) e Swap em bytes. . . . . . . . . . . . . . . . . . 46

4.7 Trecho do arquivo/proc/net/dev o qual mostra a quantidade de bytes transmitido e recebido por uma dada interface de rede desde que o computador foi ligado. . . . . . . . . . . . . . . . 47 
5.1 Movimentos possíveis do cavalo em um tabuleiro de xadrez. . . . 53

5.2 Duas soluções possíveis para o problema do passeio do cavalo em um tabuleiro $8 \times 8 \ldots \ldots \ldots \ldots \ldots$

5.3 Árvore formada no percurso do cavalo. . . . . . . . . . 56

5.4 Gráfico mostrando o tempo de execução das aplicações paralelas em um cluster balanceado. Tabuleiro solucionado de $5 \times 5$. . . . 62

5.5 Gráfico em que é mostrado o speedup das aplicações paralelas em um cluster balanceado. Tabuleiro solucionado de $5 \times 5$. . . . . 63

5.6 Gráfico mostrando o tempo de execução das aplicações paralelas em um cluster desbalanceado. Tabuleiro solucionado de $5 \times 5$. . 65

5.7 Gráfico em que é mostrado o speedup das aplicações paralelas em um cluster desbalanceado. Tabuleiro solucionado de $5 \times 5$. . . . 66

5.8 Gráfico mostrando o tempo de execução das aplicações paralelas em um cluster balanceado. Tabuleiro solucionado de $5 \times 6$. . . . 68

5.9 Gráfico em que é mostrado o speedup das aplicações paralelas em um cluster balanceado. Tabuleiro solucionado de $5 \times 6$. . . . . 69 


\section{Lista de Tabelas}

2.1 Computadores mais rápidos do mundo. Fonte [3] . . . . . . . . 9

5.1 Tempo e speedup obtidos com a execução das aplicações paralelas no cluster balanceado. Tabuleiro solucionado de $5 \times 5$. $P$ representa o número de processadores. . . . . . . . . . . . . 61

5.2 Tempo obtido com a execução das aplicações paralelas no cluster desbalanceado. Tabuleiro solucionado de $5 \times 5$. . . . . . . . . 64

5.3 Tempo e speedup obtidos com a execução das aplicações paralelas no cluster balanceado. Tabuleiro solucionado de $5 \times 6$. . . . . . 67 


\section{Resumo}

Este trabalho apresenta uma ferramenta orientada ao objeto para o monitoramento de cargas em sistemas paralelos. O desenvolvimento desta ferramenta surgiu com o intuito de facilitar a programação paralela em sistemas distribuídos como NOWs, Networks of Workstations, e Grids computacionais, pois este tipo de programação é bem mais difícil do que a seqüencial e, por isso, desestimula novos programadores a desenvolver aplicações paralelas. Dentre as razões que tornam a programação paralela difícil destaca-se o balanceamento de cargas em que se quer maximizar a utilização dos recursos computacionais do sistema distribuído. Outro motivo para o programador de aplicações paralelas se preocupar com balanceamento de cargas é o desempenho, que é drasticamente afetado com o desequilíbrio de cargas do sistema. Com relação ao tempo em que as decisões de rebalanceamento de cargas são tomadas, os algoritmos de distribuição de cargas podem ser estáticos, realizados em tempo de compilação, ou dinâmicos, efetuados em tempo de execução. Embora o algoritmo estático não gere sobrecarga em tempo de execução na distribuição de carga, o dinâmico é a melhor escolha, pois se adapta bem em qualquer situação. Assim, o sistema de monitoramento de cargas surge como uma ferramenta de auxílio ao programador que deseje implementar algoritmos de balanceamento dinâmico de cargas nas suas aplicações paralelas, provendo informações de como os recursos computacionais do sistema distribuído estão sendo utilizados. 


\section{Abstract}

This work presents an object oriented tool for load monitoring in parallel systems. This tool was developed with intention to easy the parallel programming in distributed systems like NOWs (Networks of Workstations) and Computational Grids, because this type of programming is more difficult than the sequential and, therefore, it does not stimulate new programmers to develop parallel softwares. One of the most important reasons why parallel programming is difficult is the worry about load balancing where the purpose is to maximize the use of the computational resources of the distributed system. Another reason for the programmer of parallel softwares to worry about load balancing is the performance, which is drastically affected with the load imbalance of the system. With respect to the time where the decisions of load balancing are made, the load distribution algorithms can be static, done at compilation time, or dynamic, done at execution time. Although the static algorithm does not generate overhead at execution time, the dynamic one is a better choice, because it adapts well to any situation. Thus, the monitoring system appears as a tool to aid the programmer who desires to implement dynamic load balancing algorithms in his or her parallel softwares, providing information on how the computational resources of the distributed system are being used. 


\section{CAPÍTULO \\ 1 \\ Introdução}

Nas últimas décadas, o desempenho e a capacidade dos microprocessadores têm crescido rapidamente, todavia as exigências das aplicações cresceram ainda mais do que a sua velocidade de operação. Meteorologistas querem prever o tempo com bastante precisão; farmacêuticos querem criar remédios usando computadores, reduzindo a necessidade de testá-los em cobaias; engenheiros querem usar computadores em todas as fases do desenvolvimento de aviões, sem ter que criar protótipos para testá-los em túneis de vento. Assim, apesar de todo esse poder computacional disponível atualmente, apenas um computador não tem sido suficiente para muitas aplicações, especialmente nas áreas científica, tecnológica e industrial.

Uma maneira de resolver esse problema seria melhorar a velocidade dos processadores e dos outros componentes de maneira a oferecer a potência computacional requerida pelas aplicações "pesadas" (que exigem alto poder computacional). Mesmo que isso ainda seja possível, futuros progressos estarão limitados pela velocidade da luz, pelas leis da termodinâmica e pelo alto custo de fabricação dos processadores. Além disso, a potência computacional necessária pode não estar pronta no momento desejado. Uma solução mais viável e de baixo custo é conectar vários processadores e coordenar seus esforços. O sistema resultante é 
conhecido como computador paralelo e permite a execução de programas concorrentemente.

Dentre os vários tipos de sistemas paralelos, a melhor escolha para aplicações pesadas são os multiprocessadores de memória distribuída, ou seja, o sistema descrito acima (para uma discussão mais aprofundada ver [4]). Os motivos que determinam tal escolha são o baixo custo e a escalabilidade (facilidade de expansão). Além disso, esse tipo de sistema tem proporcionado um dos melhores desempenhos, como pode ser visto em [5]. Exemplos muito importantes desse sistema são os clusters de computadores do tipo Beowulf [6] e Grid computacional [7].

Em termos de hardware, o processamento paralelo já atingiu um bom nível de maturidade que permite seu amplo uso em diversas aplicações. Entretanto, a maioria dos sistemas paralelos tem sido usada para aumento do throughput ou redução do tempo de resposta a múltiplos usuários. A razão para isto é bem clara: a programação de multiprocessadores de memória distribuída é bem mais difícil do que a de máquinas sequienciais ou de memória compartilhada. Isso ocorre porque, na programação paralela, é necessário se preocupar com as diversas linhas de controle, executando simultânea e concorrentemente, e com as suas interações. Além disso, há uma preocupação muito grande com o desempenho, pois é a única forma de se justificar a complexidade adicional do código.

Um dos fatores que limitam o desempenho é o desbalanceamento de carga computacional entre os processadores. Em multiprocessadores de memória distribuída, esse fator torna-se muito importante devido ao uso de redes de interconexão "lentas", se comparadas com os microprocessadores de alto desempenho; logo a granularidade utilizada deve ser alta para atingir boa eficiência. Com granularidade alta, as variações estatísticas da cargas tendem a ser altas também, sendo difícil otimizar a distribuição de cargas entre os processadores, principalmente diante das variações dinâmicas de carga (em tempo de execução). Além do problema da 
granularidade, em sistemas heterogêneos (computadores com desempenhos diferentes, como ocorre em Grids computacionais), há a dificuldade adicional de se atribuir a carga proporcional ao desempenho de cada computador.

A fim de garantir um desempenho satisfatório em computadores paralelos, é necessário um bom sistema de balanceamento de cargas entre os processadores. Este constitui um dos maiores desafios da computação paralela nos últimos anos, pois cada aplicação exige um tipo específico de balanceamento e desenvolver um sistema geral torna-se muito difícil.

O balanceamento de cargas implica na atribuição de carga (quantidade de tarefas ou de dados) proporcional ao desempenho de cada processador. Essa atribuição pode ser estática - realizada em tempo de compilação, ou dinâmica realizada durante a execução. Embora o balanceamento estático não gere sobrecarga (durante a execução), o dinâmico é melhor para ambientes multi-usuários em que a carga muda em tempo de execução. Portanto, é preferível que o sistema de balanceamento de cargas seja dinâmico.

Na construção de um sistema de balanceamento dinâmico de carga, é essencial a existência de um sistema de monitoramento, que seja responsável pela obtenção de informações como uso de CPU, de memória, de rede, etc, as quais serão utilizadas pelo sistema de balanceamento dinâmico de carga para tomar as devidas decisões de rebalanceamento. Deste modo, em tempo de execução, é possível saber quais processadores estão ocupados e quais estão ociosos. Na verdade, tendo um histórico da variação da carga de cada processador, é possível saber quais estão mais ocupados e quais estão menos. Portanto, é possível fazer um balanceamento de carga mais refinado, e não só redistribuir a carga dos que estão ocupados para os desocupados.

O presente trabalho consiste no desenvolvimento de um sistema de monitoramento de carga computacional de sistemas distribuídos como clusters de computa- 
dores e Grids computacionais. Deste modo, sabendo a carga de cada computador de um sistema paralelo, o programador poderá distribuir eficientemente as cargas entre eles em tempo de execução, embora essa seja uma tarefa difícil mesmo para os mais experientes.

O monitoramento de cargas também pode ser útil para o escalonamento de processos em sistemas distribuídos, em que a informação de carga dos processadores é importante para tomar as devidas decisões de distribuição de processos entre os processadores (esta constitui a política de informação no escalonamento de processos, conforme será visto no capítulo 3).

O sistema de monitoramento foi desenvolvido utilizando-se o modelo cliente/servidor, em que o servidor é responsável pela obtenção das informações de carga de cada computador e o cliente é o que pede essas informações remotamente. Um tipo de cliente possível é uma central de informações de cargas de todos os computadores de um sistema distribuído. Neste caso, quando o programador desejar saber quais computadores estão mais ocupados sob um determinado tipo de carga, basta acessar os dados obtidos pela central.

\subsection{Organização da dissertação}

Capítulo 2 Neste capítulo será realizada uma breve introdução à computação paralela, expondo as arquiteturas mais comuns e as que predominam atualmente, as questões relacionadas com a programação paralela, como algumas ferramentas e linguagens existentes, e algumas medidas de eficiência das aplicações paralelas.

Capítulo 3 Este capítulo será uma revisão da literatura sobre distribuição de cargas em sistemas distribuídos e procurará expor as dificuldades envolvidas na construção de um sistema de balanceamento de cargas e mostrar onde um 
sistema de monitoramento de cargas é necessário.

Capítulo 4 Neste capítulo, o sistema de monitoramento de cargas desenvolvido neste trabalho de mestrado será descrito em detalhes, justificando as ferramentas utilizadas e explicando as partes mais importantes desse sistema.

Capítulo 5 Neste capítulo, descrever-se-á como foi testado o sistema de monitoramento de cargas e discutir-se-ão os resultados obtidos nos testes.

Capítulo 6 Este capítulo abordará as conclusões deste trabalho e apresentará propostas para a sua continuação e trabalhos futuros. 


\section{CAPÍTULO \\ 2 \\ Computação Paralela}

Na década de 1980, acreditava-se que o desempenho computacional seria melhorado através da criação de processadores mais rápidos e mais eficientes. No entanto, essa idéia foi desafiada pelo processamento paralelo, cuja essência consiste em conectar dois ou mais computadores para resolver, conjuntamente, um problema computacional.

No começo da década de 1990, houve uma tendência de migração dos supercomputadores paralelos proprietários (supercomputadores vetoriais e processadores fortemente paralelos) para redes de computadores (PCs/workstations/SMPs). Isso ocorreu devido ao desenvolvimento rápido dos componentes de alta performance para PCs/workstations e das redes de intercomunicação. Essas tecnologias permitiram às redes e aos clusters de computadores se tornarem a melhor escolha em custo-desempenho para a computação paralela.

Neste capítulo, serão apresentados: os diferentes tipos de computadores paralelos numa breve descrição de suas arquiteturas, além de mencionar as arquiteturas mais comuns atualmente e a sua relação com o balanceamento de cargas; os problemas presentes no desenvolvimento de softwares paralelos e uma metodologia para ajudar nessa tarefa; as ferramentas e as linguagens para programação paralela disponíveis atualmente; e algumas medidas de desempenho para programas 
paralelos.

\subsection{Arquitetura de computadores paralelos}

Com o avanço da tecnologia em hardware e da computação paralela, foram propostas diferentes maneiras de se conectar os recursos computacionais, criando-se diferentes arquiteturas paralelas. Cada arquitetura apresenta características próprias, porém, sempre com o intuito de buscar melhores desempenhos. Para acompanhar o desenvolvimento das arquiteturas paralelas e agrupar computadores paralelos com características comuns, foram propostas algumas classificações, dentre elas a de Flynn (1972) [8]. A classificação de Flynn, embora antiga, é amplamente utilizada e se baseia no fluxo de instruções e no fluxo de dados, originando quatro categorias: SISD (Single Instruction Stream, Single Data Stream), SIMD (Single Instruction Stream, Multiple Data Stream), MISD (Multiple Instruction Stream, Single Data Stream) e MIMD (Multiple Instruction Stream, Multiple Data Stream).

O esquema conhecido como SISD é utilizado apenas para máquinas clássicas de Von Neumann no qual existe uma única sequiência de instruções e uma única sequiência de dados. Já as máquinas SIMD têm apenas uma unidade de controle que trata uma instrução de cada vez, mas possuem várias unidades de processamento que podem executar essa instrução em vários conjuntos de dados simultaneamente.

A categoria MISD é muito estranha, pois pressupõe que várias instruções operem sobre o mesmo dado. Não existe nenhum computador que possa ser classificado nessa categoria. Já as máquinas MIMD são um conjunto de processadores independentes que processam dados diferentes. A maioria dos computadores paralelos atuais pertence a esta categoria. 


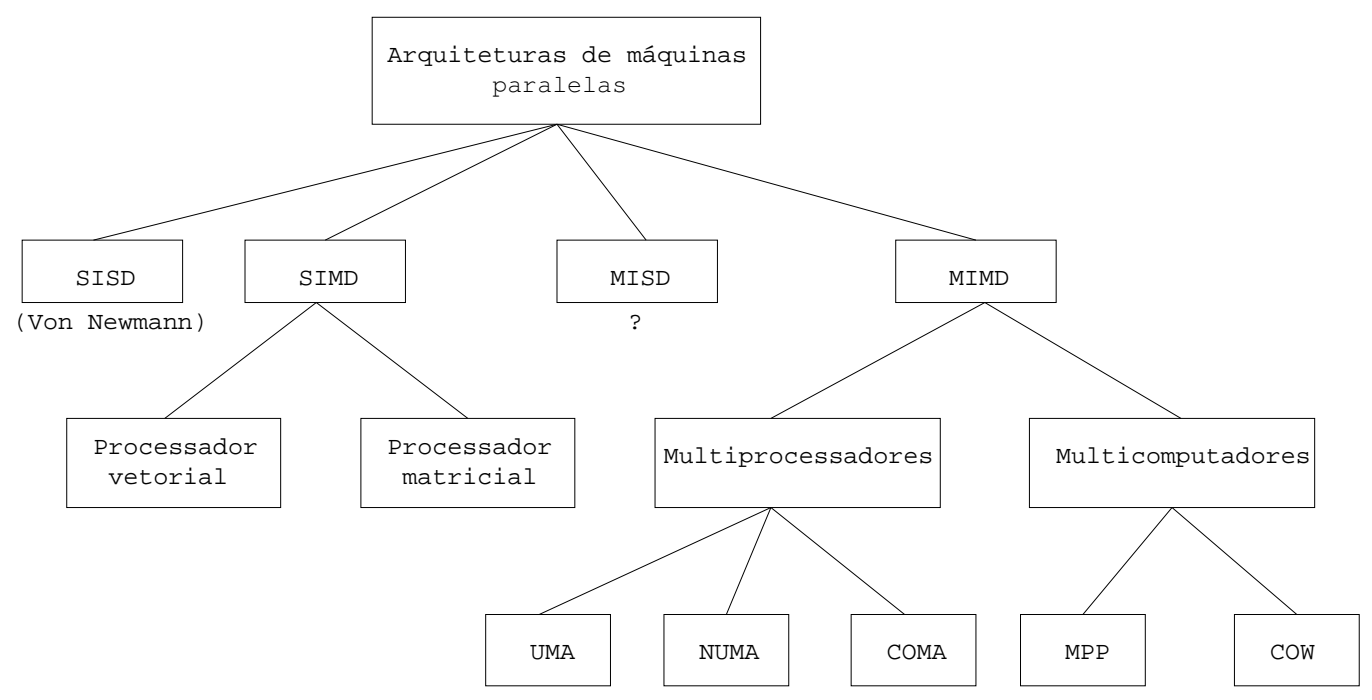

Figura 2.1: Taxionomia para máquinas paralelas. Fonte [1].

Com o intuito de melhorar a taxionomia de Flynn, Tanenbaum [1] estendeu-a, conforme mostra a figura 2.1. As máquinas SIMD foram subdivididas em dois subgrupos: processadores matriciais e vetoriais. Nos dois tipos, uma instrução simples resulta em operações idênticas sendo executadas em dados diferentes. Nas máquinas vetoriais, um processador simples funciona como um computador SIMD. Embora não estritamente um computador paralelo no sentido de várias máquinas trabalhando juntas, processadores vetoriais realizam operações em paralelo de um modo que, às vezes, é descrito como "paralelismo de dados". Em contrapartida, processadores matriciais compreendem um grande número de processadores muito simples. Este tipo de máquina não é muito popular atualmente [4].

A categoria MIMD foi dividida em multiprocessadores, máquinas com memória compartilhada, e multicomputadores, máquinas com mecanismo de troca de mensagens. Quanto à maneira como a memória compartilhada é implementada, os multiprocessadores são subdivididos em três tipos: UMA (Uniform Memory Access, acesso uniforme à memória), NUMA (NonUniform Memory Access, acesso não-uniforme à memória) e COMA (Cache Only Memory Access, acesso 
Tabela 2.1: Computadores mais rápidos do mundo. Fonte [3]

\begin{tabular}{|c|c|c|c|}
\hline Periodo & Supercomputador & Velocidade & Localização \\
\hline \hline $1943-1944$ & Colossus & & Bletchley Park, England \\
\hline $1945-1950$ & Manchester M. I & & University of Manchester, England \\
\hline $1950-1955$ & MIT Whilwind & & Massachusetts Inst. of Tech., Cambridge \\
\hline $1955-1960$ & IBM 7090 & 210 KFLOPS & U.S. Air Force, Rome, NY \\
\hline $1960-1965$ & CDC 6600 & 10.2 MFLOPS & Lawrence Livermore Lab., California \\
\hline $1965-1970$ & CDC 7600 & 37.3 MFLOPS & Lawrence Livermore Lab., California \\
\hline $1970-1975$ & CDC Cyber 76 & & \\
\hline $1975-1980$ & Cray-1 & 160 MFLOPS & Los Alamos Nat. Lab., New Mexico \\
\hline $1980-1985$ & Cray X-MP & 500 MFLOPS & Los Alamos Nat. Lab., New Mexico \\
\hline $1985-1990$ & Cray Y-MP & 1.3 GFLOPS & Los Alamos Nat. Lab., New Mexico \\
\hline $1990-1995$ & Fujitsu N. W. T. & 236 GFLOPS & \\
\hline $1995-2000$ & Intel ASCI Red & 2.15 TFLOPS & Sandia Nat. Lab., New Mexico \\
\hline $2000-2002$ & IBM ASCI & 7.23 TFLOPS & Lawrence Livermore Lab., California \\
\hline $2002-2003$ & Earth Simulator & 35 TFLOPS & Yokohama Inst. for E. S., Japan \\
\hline
\end{tabular}

à memória somente por intermédio da cache).

A outra categoria de MIMD, os multicomputadores, ao contrário dos multiprocessadores, não possuem memória compartilhada no nível de arquitetura. Neste sistema, cada processador possui sua própria memória, a qual não pode ser acessada diretamente pelos outros processadores. O processamento paralelo é, então, facilitado por passagem explícita de mensagens que será discutida mais tarde. Os sistemas multicomputadores podem ser divididos em duas categorias: sistemas MPP (Massively Parallel Processors, processadores fortemente paralelos), ou NOW (Network Of Workstations, redes de computadores), COW (Cluster Of Workstations, cluster de computadores) e Grids computacionais. NOWs e COWs são os sistemas formados por computadores pessoais interligados por intermédio de redes comerciais. Já Grids computacionais [7] são redes de computadores geograficamente distribuídas e administração separada.

Dentre os computadores paralelos desenvolvidos, os mais importantes atual- 
mente são os MIMD: multiprocessadores, ou computadores de memória compartilhada e os multicomputadores, ou computadores de memória distribuída. Um caso especial é o Earth Simulator [9], pois, além de ser o computador mais rápido do mundo [5] com desempenho superior a 35 Tflops/s (a tabela 2.1 mostra os computadores mais rápidos do mundo ao longo do tempo), é um computador paralelo do tipo MIMD constituído de computadores vetoriais, ao invés de computadores seqüenciais como ocorre com os multicomputadores. E, dentre os computadores MIMD, os multicomputadores (NOWs, COWs e Grids computacionais) vêm se tornando a melhor escolha em computação de alto desempenho, devido aos motivos expostos no começo deste capítulo: melhor custo-desempenho, escalabilidade (facilidade de expansão) e a existência de ferramentas de programação para esses sistemas como MPI, as quais serão discutidas mais tarde.

Nesses sistemas, como o custo de comunicação entre os computadores é alto (em relação ao poder de processamento deles), é necessário dividir a aplicação paralela em pedaços grandes (granularidade alta) a fim de melhor aproveitar o poder de processamento de cada computador, reduzindo a quantidade de comunicação entre eles. Com isso, fica difícil distribuir igualmente a quantidade de trabalho (carga) entre os computadores. Além disso, Livny e Melman [10] mostraram que até em sistemas homogêneos, pelo menos um computador é provável estar ocioso enquanto os outros estão sobrecarregados por causa das flutuações estatísticas na criação de tarefas nos computadores e os requerimentos dessas tarefas. Essa dificuldade se agrava ainda mais em sistemas multi-usuários formados por computadores heterogêneos em que é impossível prever a variação da carga em tempo de compilação (antes da aplicação ser executada). 


\subsection{Programação paralela}

Embora a tecnologia de sistemas distribuídos esteja sendo desenvolvida, o desenvolvimento de aplicações paralelas é realmente uma tarefa difícil. Primeiro, a programação paralela é muito dependente da arquitetura e das ferramentas disponíveis. Segundo, os programadores de softwares paralelos precisam se preocupar com problemas não presentes na programação seqüencial como: nãodeterminismo, comunicação, sincronização, distribuição e particionamento de dados, balanceamento de cargas, tolerância a falhas, heterogeneidade, memória distribuída ou compartilhada, deadlocks e condições de corrida.

Realmente, não existe "receita" fácil para o desenvolvimento de softwares paralelos. De uma maneira simples, desenvolver uma aplicação paralela significa dividir o problema em partes que podem ser executadas em paralelo. Entretanto, há uma metodologia criada por Ian Foster [11] que maximiza o leque de opções, provê mecanismos para cálculo de alternativas e reduz a quantidade de escolhas erradas. Tal metodologia permite ao programador se preocupar com questões independentes de máquina, como concorrência, nos estágios iniciais do desenvolvimento, e com aspectos específicos de máquina nos estágios finais. Como sugerido por Ian Foster, esta metodologia se divide em quatro estágios distintos:

Particionamento - decomposição dos dados e/ou dos cálculos em várias tarefas pequenas;

Comunicação - estudo do fluxo de informações e da coordenação entre as tarefas criadas no estágio anterior;

Aglomeração - agrupamento das tarefas dos estágios anteriores em tarefas mai- 
ores a fim de melhorar o desempenho e reduzir o custo de desenvolvimento;

Mapeamento - alocação das tarefas nos processadores de maneira a maximizar o uso dos recursos do sistema (como por exemplo, uso de CPU).

As decisões de mapeamento podem ser tomadas estaticamente (em tempo de compilação, antes da execução do programa) ou dinamicamente (em tempo de execução) através de métodos de balanceamento de cargas, como será discutido no capítulo 3.

A programação paralela é realmente uma tarefa muito difícil mesmo para quem é experiente na área, e a preocupação com balanceamento de cargas é uma questão fundamental para obter alto desempenho. Na próxima seção, serão apresentadas algumas ferramentas e linguagens para programação paralela e o que elas fazem com relação ao balanceamento de cargas.

\subsection{Ferramentas e linguagens para programa- ção paralela}

\subsubsection{Bibliotecas de comunicação entre processos}

Esta é a forma mais utilizada em programação paralela. Neste método, é fornecido ao programador um conjunto de rotinas que permite realizar a comunicação e sincronizar a operação entre processos ou threads distintos. Exemplos típicos e importantes são o padrão MPI [12] de comunicação por passagem de mensagens e o Posix Threads $[13,14]$ de comunicação por memória compartilhada.

Como estão próximos da implementação em hardware (por exemplo, um processo de MPI pode corresponder a um processo do sistema operacional e uma mensagem MPI pode corresponder ao envio de dados pela rede) esses métodos 
têm implementação facilitada e permitem atingir bons desempenhos, o que justifica sua preferência atualmente. Entretanto seu baixo grau de abstração do hardware dificulta consideravelmente o desenvolvimento de sistemas paralelos. De fato, o programador MPI precisa se preocupar não só com algoritmo paralelo, mas também com detalhes como: o instante em que uma comunicação deve ocorrer (tanto do lado do remetente como do lado do destinatário); quais os dados a enviar (seu tipo, quantidade e layout em memória); se a comunicação deve ser bloqueante (retorna apenas quando a comunicação foi efetuada) ou não-bloqueante (retorna imediatamente); qual o número do processo onde os dados se encontram ou para o qual os dados se destinam; se a mensagem que está sendo enviada não pode ser confundida com outra mensagem enviada ao mesmo processo. Isso faz com que a implementação, mesmo de algoritmos paralelos simples, seja complexa e sujeita a erros, consumindo muito tempo na implementação e desencorajando a experimentação com algoritmos diferentes.

Para lidar com o balanceamento de cargas, o programador deve em geral implementar em seu código os mecanismos necessários para um bom resultado, por exemplo, através da análise da quantidade de cálculos efetuada por cada processo e da migração de tarefas para outros processadores quando necessário, ou usando técnicas de distribuição cíclica das tarefas entre os processadores. Em suma, não existe nenhum sistema de apoio para ajudar no balanceamento de cargas usando esse tipo de biblioteca; fica, portanto, a cargo do programador realizar tal tarefa.

\subsubsection{Compiladores paralelizantes}

Aqui a idéia é facilitar ao máximo o trabalho do programador, e aproveitar a grande quantidade de códigos seqüenciais existentes. Um compilador especial pega um código escrito sem preocupação com paralelismo e tenta extrair, através de análises de dependência e de diversas técnicas [15], um código paralelo. 
Exemplos de compiladores paralelizantes são o SUIF [16] e o PARADIGM [17].

Apesar da inegável vantagem em termos de programação e reaproveitamento de código, este método tem se mostrado longe de ótimo devido à dificuldade de extração de paralelismo eficiente de um código seqüencial. De fato, ao escrever um código seqüencial o programador elimina diversas características de concorrência presentes originalmente no problema, que não podem ser recuperadas a partir do código apresentado (pois o compilador é forçado a manter a semântica do código para evitar a introdução de erros).

Com relação ao balanceamento de cargas, este é raramente considerado no processo de paralelização e, quando o é, isto só ocorre para o paralelismo de granularidades muito baixas e em tempo de compilação, inadequadas para a execução em clusters ou em Grids computacionais.

\subsubsection{Linguagens de paralelismo implícito}

Uma forma de solucionar o problema da eliminação de paralelismo durante a programação, citado anteriormente, é utilizar-se de linguagens que não forçam uma semântica seqüencial. Dentre essas linguagens têm-se as linguagens funcionais (por exemplo, Haskell [18] e Sisal [19]) e as linguagens lógicas (por exemplo, Prolog [20]). Essas linguagens evitam a seqüencialização não especificando a ordem em que as operações devem ser executadas mas sim as relações semânticas entre essas operações. Desta forma, a extração do paralelismo é mais simples. Entretanto conseguir paralelismo eficiente em máquinas atuais (que requerem bom balanceamento de cargas e granularidade grossa) continua um desafio, como demonstrado por recentes propostas de inserção de alguma forma de paralelismo explícito em linguagens desse tipo [21,22].

Apesar de facilitar o trabalho do compilador paralelizante, esta solução não ajuda a atingir o objetivo de uma boa distribuição de cargas, já que os mesmos 
problemas da paralelização de códigos seqüenciais permanecem.

\subsubsection{Linguagens de paralelismo explícito}

Para evitar os problemas de tentativa de extração automática de paralelismo e ao mesmo tempo evitar a programação em nível de detalhes muito baixo, diversas linguagens de programação com paralelismo explícito foram propostas (ver [23] para um revisão relativamente recente). Essas linguagens variam amplamente quanto à abstração de paralelismo oferecida ao programador. Será citado aqui apenas um grupo importante, que explora a semelhança entre processos que se comunicam e objetos em um linguagem orientada a objetos: um objeto encapsula estado interno do meio exterior e somente interage com outros objetos por meio de chamadas de métodos (denominados em orientação a objetos envio de mensagens). Assim, essas linguagens abstraem paralelismo considerando objetos como unidades de execução paralela e realizando sincronização e comunicação entre os diferentes objetos por meio de seus métodos. Um exemplo é a linguagem Mentat [24]. Entre os problemas com essa abordagem pode-se citar:

1. A necessidade de aprender uma nova linguagem é um poderoso inibidor, que somente será de pouca importância se os benefícios adicionais oferecerem compensação suficiente;

2. O desenvolvimento de uma linguagem com uma semântica coerente, clara e poderosa é uma tarefa difícil, o que inibe mudanças na linguagem, necessárias para adaptá-las a diferentes condições arquiteturais;

3. Não existe na comunidade da área, em parte devido à grande diversidade de aplicações de processamento paralelo, um consenso sobre que tipo de construção semântica pode ser incorporado com vantagens a uma linguagem, de 
forma a permitir a geração de código eficiente e ao mesmo tempo facilitar o desenvolvimento dos programas.

Com respeito ao balanceamento de cargas, essas linguagens costumam tomar uma de duas atitudes: ou deixam o trabalho por conta do programador (que deve se preocupar, então, com o problema como se estivesse programando em um nível mais baixo de abstração) ou então fornecem sistemas de execução que permitem a criação de objetos independentes que podem ser executados em qualquer processador, e determinam apenas em tempo de execução onde cada objeto deve executar. No primeiro caso, o problema continua não resolvido, apesar de sua solução pelo programador poder ser facilitada; no segundo caso, para desenvolver uma boa distribuição de cargas o programador deve apenas conseguir descrever seu problema em termos de uma quantidade suficientemente grande de tarefas independentes, de forma que uma quantidade mais ou menos igual de carga possa ser distribuída pelo sistema para cada processador. No segundo caso, infelizmente, em geral, não são dados aos programadores elementos para influenciar a distribuição das tarefas, o que pode levar a distribuições sub-ótimas para casos especiais, situação que poderia ser evitada através da intervenção do programador.

\subsubsection{Sistemas voltados a área específica}

Nesta categoria, incluem-se os sistemas que apresentam uma biblioteca de rotinas e, possivelmente, ambientes de desenvolvimento para auxiliar a implementação de códigos paralelos para programas de um dado tipo, podendo este ser de caráter mais geral ou mais específico. Um exemplo de sistema de caráter mais geral é a biblioteca ScaLapack [25], voltada a problemas que possuem cálculos baseados em matrizes; um exemplo de sistema de caráter mais específico é Cactus [26], inicialmente desenvolvido para estudos de relatividade numérica e que está sendo expandido para aplicações mais gerais. Este tipo de solução é promissor, pois 
permite associar desempenho com facilidade de programação. O problema é a dificuldade de reutilização do esforço para outras áreas de aplicações.

Neste caso, a tarefa de balanceamento de cargas fica por conta do programador das bibliotecas, sendo que o usuário precisa apenas cuidar para que a execução de outras partes de seu código não influenciem o balanceamento de cargas das rotinas utilizadas. O problema com esta solução é que ela serve apenas para casos individuais, cujos algoritmos já tenham sido implementados e otimizados. Para um programador que precise desenvolver um novo código ou uma versão um tanto diferente dos existentes não é fornecido nenhum apoio.

\subsection{Medidas de desempenho de algoritmos pa- ralelos}

Speedup e eficiência são duas maneiras de se medir o desempenho de algoritmos paralelos [11]. Speedup é a razão entre o tempo de execução da versão seqüencial de um programa em um processador e o tempo de execução do mesmo programa (versão paralela) em $p$ processadores. Se $T_{p}$ é o tempo de execução de um programa paralelo em $p$ processadores e $T_{0}$ é o tempo de execução do algoritmo seqüencial mais rápido em um processador simples, $S_{p}$, o speedup de $p$ processadores, é dado por:

$$
S_{p}=\frac{T_{0}}{T_{p}}
$$

Note que essa definição de speedup compara apenas um algoritmo paralelo com o algoritmo seqüencial mais rápido de um dado problema. Uma definição alternativa fornece a razão entre o tempo de execução de um programa paralelo em $p$ processadores e o de 1 processador. De qualquer forma, o ideal é que o speedup varie linearmente com o número de processadores, ou seja, o speedup de 
$p$ processadores seja $p$.

Uma outra forma de medir o desempenho de um algoritmo paralelo é através da eficiência, uma medida do uso efetivo do hardware, igual à razão entre o speedup de $p$ processadores e $p$. Se $S_{p}$ é o speedup e $p$ é o número de processadores, então a eficiência, $E_{p}$, é dada por:

$$
E_{p}=\frac{S_{p}}{p}
$$

Um $E_{p}$ próximo de 1 significa que o programa paralelo é escalável. Próximo de zero, porém, indica que o programa paralelo é pouco escalável. Podem acontecer casos em que o speedup tenda a um certo limite a partir do qual, o uso de mais processadores não reduz muito o tempo de execução de um programa paralelo. Nesse caso, a eficiência tende a zero, logo o programa é pouco escalável.

\subsection{Resumo do Capítulo}

Neste capítulo, foi indicado que os computadores paralelos que predominam atualmente são os NOWs, COWs e Grids computacionais devido à relação custodesempenho, escalabilidade e a existência de ferramentas portáveis como MPI e o que isso implica no tamanho da cargas a serem divididas entre os computadores. Em seguida, foram apresentadas as questões que dificultam a programação paralela e uma metodologia para desenvolver softwares paralelos. Foi visto que a programação paralela não é uma tarefa fácil e que há uma necessidade muito grande de desenvolver ferramentas para auxiliar o programador nesse empreendimento como um sistema de balanceamento de cargas já que as ferramentas e as linguagens existentes para programação paralela não dão conta disso. O balanceamento de cargas é o assunto a ser discutido no próximo capítulo. 


\section{CAPÍTULO \\ 3 \\ Balanceamento de Cargas}

\subsection{Considerações iniciais}

Inicialmente, é necessário definir o significado de balanceamento de cargas. Do dicionário Aurélio [27], balancear significa: balançar, equilibrar, contrapesar, contrabalançar. Tal significado se encaixa perfeitamente no contexto de computação paralela no qual balanceamento de cargas significa equilibrar as cargas entre os processadores. O objetivo de um algoritmo de balanceamento de cargas é maximizar a utilização dos recursos computacionais (processadores) a fim de obter alto desempenho [28]. Entretanto, balanceamento de cargas é apenas um dos objetivos de um algoritmo de escalonamento de processos. Já o conceito de carga computacional diz respeito ao quanto os recursos computacionais (como, CPU, memória, etc) estão ocupados.

Outra questão importante no processo de distribuição de cargas é diferenciar balanceamento de cargas (Load balancing) de compartilhamento de cargas (Load Sharing) [28]. O primeiro tenta garantir que cada processador do sistema realiza a mesma quantidade de trabalho em qualquer instante. Pode ser necessária a migração de processos de uma máquina para outra até mesmo no meio da execução para garantir carga igual entre os processadores. A sobrecarga imposta por um 
algoritmo de balanceamento de cargas pode contrabalançar qualquer melhora ganha no desempenho por esse esquema por causa do custoso processo de migração de processos. O segundo é uma versão mais simples do primeiro o qual tenta iniciar um processo novo no processador menos ocupado, sem migrar processos no meio da execução. Embora compartilhamento de cargas não garanta distribuição equilibrada de cargas entre os nós do sistema, ele é mais simples de implementar e pode acomodar com mais facilidade a heterogeneidade do sistema.

Nesse contexto de distribuição de cargas entre os processadores, essas duas formas de migração de processos são geralmente conhecidas como preemptiva e não-preemptiva respectivamente. Naturalmente, migração não-preemptiva de processos pode ser mais facilmente implementada do que a preemptiva, pois a segunda requer a checagem do estado de um processo já em execução e, então, transferir esse estado para a máquina destino. Esse é um problema realmente muito difícil se as duas máquinas envolvidas no processo de transferência tiverem arquiteturas diferentes. Além disso, esse processo é muito custoso porque o estado completo (o qual pode ser muito grande) tem de ser transferido. Estudos têm mostrado que a sobrecarga adicional restringe severamente os benefícios do desempenho obtido pela transferência preemptiva de processos se comparado à migração não-preemptiva de processos [29]. Migração não-preemptiva de processos não impõe esse custo adicional, pois somente as tarefas recém-submetidas são transferidas para as outras máquinas.

Os esquemas de distribuição de cargas são geralmente divididos em: política e mecanismo. A política é o conjunto de escolhas que são feitas para distribuir as cargas. O mecanismo realiza a distribuição física das cargas e provê qualquer informação requerida pelas políticas (uma útil analogia é a separação mente-corpo).

Este capítulo se preocupará apenas com as políticas de migração de processos, pois são elas que regem os processos de distribuição de cargas e que podem utilizar 
o sistema de monitoramento de cargas desenvolvido neste trabalho de mestrado.

\subsection{Políticas para o compartilhamento de car- gas}

O escalonamento de tarefas de um sistema distribuído que implementa compartilhamento de cargas precisa de dois componentes: um distribuidor (allocator) e um escalonador (scheduler) [30]. O distribuidor é responsável por decidir onde uma tarefa deve ser executada e o escalonador, quando ela deve ser executada. Em sistemas distribuídos, geralmente cada nó possui seu próprio escalonador, pois seu sistema operacional já faz isso, ao passo que as decisões mais importantes de atribuir uma tarefa a um nó são realizadas pelo distribuidor. O distribuidor e o escalonador implementam a política de distribuição e a de escalonamento respectivamente.

A política de distribuição tenta distribuir toda a carga do sistema para seus nós individuais, transferindo processos entre eles. Já a política de escalonamento pode funcionar da mesma forma que a do sistema operacional: checar o conjunto de processos disponíveis em execução e escolher o processo mais adequado para executar a fim de maximizar o throughput total. Como o escalonamento geralmente é feito pelo sistema operacional (algumas exceções são possíveis, como co-escalonamento $[31,32])$, o restante desta seção se concentrará apenas nas políticas de distribuição.

De fato, a política de distribuição não desempenha migração de processos. Ela apenas ajuda o mecanismo de migração de processos provendo informações do tipo: quando um nó precisa tentar migrar um processo, qual processo deve ser esse, qual nó deve receber esse processo, etc. Além disso, os módulos de cada nó que implementam tais políticas trocam informações sobre o estado atual da carga 
dos outros nós a fim de tomar decisões mais adequadas.

\subsubsection{Propriedades desejáveis para as políticas}

Os objetivos de uma política de distribuição de cargas dependem das metas do usuário. Tais objetivos podem ser: maximizar a utilização dos recursos (como CPU); minimizar o tempo de resposta médio de processos; minimizar a razão de resposta de processos; minimizar sobrecarga de intercomunicação entre processos; aumentar throughput; tornar o sistema tolerante a falhas; entre outros. Além desses objetivos, uma política deve ser de implementação simples e sensível às mudanças de cargas do sistema.

\subsubsection{Medidas de carga computacional}

Medir a carga dos processadores num sistema distribuído é um dos processos mais importantes de um algoritmo de distribuição de cargas e também um dos mais difíceis. Geralmente, a carga de um nó é medida em termos do índice de carga, como definido em [28]. Vários tipos de medidas foram estudados como: tamanho da fila de processos de cada processador, média dessa fila sobre um certo período de tempo, a quantidade de memória disponível, utilização da CPU, atraso na comunicação, etc. Além disso, um bom candidato para índice de carga deve ser fácil de se calcular e deve se correlacionar bem com o que se quer otimizar (por exemplo, maximizar o uso dos recursos). Kunz [33] mostrou que índices de carga simples são mais efetivos e que um dos mais efetivos é o tamanho da fila de

processos. Recentemente, Mello, Paiva e Trevelin [34] mostraram que o índice de carga baseado na análise da utilização de CPU e de memória é também bastante efetivo.

Em sistemas heterogêneos, os índices de carga de nós diferentes arquiteturalmente devem ser ajustados a fim de serem comparados. Por exemplo, se dois 
processadores possuírem poderes computacionais diferentes, a utilização da CPU deve ser dividida por seus respectivos poderes computacionais para seus índices de carga serem comparados adequadamente.

\subsubsection{Componentes das políticas}

Um algoritmo de compartilhamento de cargas pode ser dividido em quatro componentes: política de transferência, política de seleção, política de localização e política de informação [28].

A política de transferência determina quando um nó se torna apropriado para participar de uma transferência de processos, seja como remetente seja como destinatário. A maioria dos algoritmos de compartilhamento de cargas utiliza política de limiar como política de transferência. Essa política designa um nó como sendo remetente se o seu índice de carga exceder um certo limiar $T_{1}$ ou como sendo destinatário se o seu índice de carga ficar abaixo de um outro limiar $T_{2}\left(T_{1} \geq T_{2}\right)$. Uma outra política de transferência possível é a política relativa, a qual define dois nós como sendo remetente ou destinatário dependendo da diferença relativa entre os seus índices de carga.

Enquanto que a política de transferência determina que nó será o remetente, a política de seleção determina qual processo do remetente deve ser transferido. No caso mais simples de migração não-preemptiva de processos, a política de seleção escolhe o processo mais recente a ser executado no remetente para ser transferido. No caso de migração preemptiva de processos, a política de seleção deve escolher processos menores (de maneira que a sobrecarga originada na transferência seja pequena), de vida longa (de maneira que justifique a sobrecarga de transferência) e que façam poucas chamadas de sistema dependentes do remetente.

A política de localização se encarrega de encontrar um parceiro (destinatário) para o remetente. Uma política de localização muito comum é a pesquisa (do 
inglês polling). A pesquisa pode ser serial ou paralela com respeito a quantos nós podem ser pesquisados em um determinado instante (pesquisa paralela requer do sistema facilidades de passagem de mensagens de multi-cast ou de broadcast) e aleatória ou baseada no vizinho mais próximo. Dentre as outras opções para a política de localização estão os pedidos de broadcast em que um nó transmite uma mensagem e o mais apto destinatário responde, tornando-se o parceiro do remetente. Uma política centralizada, onde existe um coordenador para escolher o parceiro para o remetente, também pode ser usada.

A política de informação é responsável por recolher informações dos nós do sistema para ser usado nas decisões de distribuição de processos. O objetivo deste componente é realizar decisões mais precisas, embora ele sobrecarregue o sistema. Há várias questões relacionadas à política de informação, a saber, que informação precisa ser coletada, onde essa informação deve ser guardada e quando realizar a coleta.

Geralmente, a informação a ser coletada é somente a carga e os recursos disponíveis dos nós do sistema. A informação pode ser coletada por apenas um nó (algoritmo centralizado) ou pode ser total ou parcialmente coletada por todos os nós (algoritmo descentralizado). A coleta de informação freqüente ajuda a tomar melhores decisões de distribuição de cargas, todavia a sobrecarga no sistema é maior. A coleta de informação pode ser: guiada pela demanda em que o nó recolhe informação sobre os outros somente quando necessário; periódica, em que a informação é recolhida periodicamente; e guiada pelo estado do nó, em que os nós transmitem a informação sobre seus estados quando eles mudam num certo grau. 


\subsubsection{Estabilidade e eficiência}

Embora maximizar a utilização dos recursos seja um dos objetivos primordiais de um algoritmo de compartilhamento de cargas, manter todas as condições necessárias para isso representa um dos maiores desafios para os programadores desses algoritmos. Em geral, os algoritmos de compartilhamento de cargas têm bom desempenho quando a carga do sistema é baixa, ao passo que o desempenho diminui drasticamente com carga alta. Isso ocorre porque o tempo perdido pelo distribuidor de tarefas em realizar uma "boa" distribuição de cargas pode ser grande quando a carga do sistema é alta.

Na perspectiva teórica de enfileiramento de tarefas, quando a taxa de chegada de tarefas é maior do que a taxa que o sistema é capaz de processar, a fila do processador cresce sem limites e tal sistema é chamado de instável. No contexto dos algoritmos de compartilhamento de cargas, o enunciado acima pode ser refeito como "se a soma da carga devida à chegada de trabalhos externos ao sistema com a carga devida à sobrecarga imposta pelo algoritmo de compartilhamento de cargas for maior que a potência total de processamento do sistema, o sistema se torna instável..." [28].

Um algoritmo é dito eficiente sob um conjunto de condições se ele melhorar o desempenho relativo ao sistema que não usa esse algoritmo. Na perspectiva algorítmica, se um algoritmo executa ações inúteis indefinidamente, então ele é ineficiente. Verifica-se que um algoritmo pode ser estável embora não seja eficiente, mas algoritmos eficientes são estáveis. Assim, é desejável que a solução de um problema de distribuição de processos seja eficiente além de ser estável $[35,36]$. 


\subsubsection{Classificação}

Várias políticas de compartilhamento de cargas ou algoritmos de distribuição de processos foram propostas no passado [30]. Como são muitos algoritmos diferentes, uma classificação se faz útil para melhor compreender as questões envolvidas e para comparação entre eles. Várias foram as tentativas de classificação dos algoritmos de distribuição de processos desenvolvidas [37, 38, 39, 40, 41], todavia aqui será apresentada apenas a proposta por Casavant e Khul [37] por ser uma das mais usadas atualmente. A figura 3.1 mostra tal classificação. As próximas subseções discutirão brevemente as várias opções de desenvolvimento dos algoritmos de distribuição propostos nessa classificação.

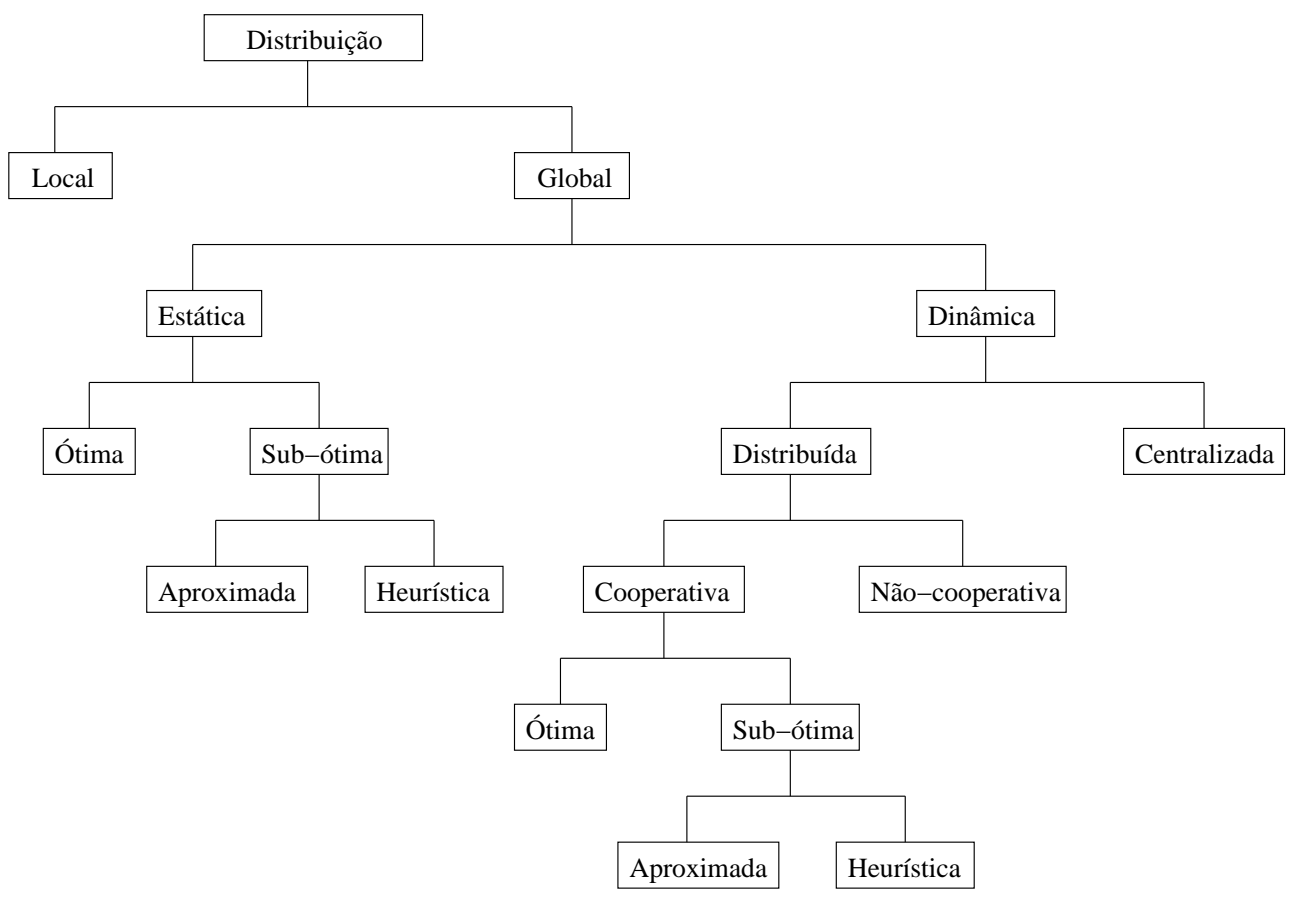

Figura 3.1: Classificação da distribuição de cargas. 


\section{Distribuição global e local}

No nível mais alto da hierarquia, algoritmos gerais de distribuição de processos são divididos em locais e globais. Os globais são, em geral, referenciados na literatura como os algoritmos de distribuição de processos entre os processadores de um sistema distribuído. Os locais são os algoritmos usuais de escalonamento de processos usados em sistemas operacionais centralizados, portanto sem importância nesta classificação.

\section{Estática e dinâmica}

A distribuição de processos entre os processadores pode ser dinâmica ou estática, dependendo do tempo em que a distribuição é feita. Distribuição estática é mais de interesse teórico do que prático, pois assume que informação de carga do sistema e os requerimentos de recursos de um programa estejam disponíveis no momento de compilação do programa e, portanto, a escolha do processador que executará um certo processo é decidido nesse instante. Distribuição dinâmica considera a informação do estado atual e prévio do sistema para tomar as decisões de distribuição de processos e, portanto, prover melhores resultados do que a estática. Por essa razão, não serão discutidas as subclassificações da distribuição estática.

\section{Distribuído e centralizado}

Aqui, a preocupação é com quem toma as decisões de distribuição de processos. Se a decisão for feita por apenas um nó, a distribuição é centralizada, ou se for compartilhada por vários, ela é distribuída. Algoritmos centralizados são mais simples de implementar, mas não escalam bem, pois o coordenador pode se tornar o gargalo do sistema, além de ser um ponto crítico de falha, a qual não pode ser tolerada em sistemas distribuídos. 


\section{Cooperativo e não-cooperativo}

Os algoritmos distribuídos podem ainda ser subdivididos em cooperativos e nãocooperativos. A questão aqui está relacionada com o grau de autonomia de cada nó em determinar como os seus próprios recursos serão utilizados. No caso nãocooperativo cada processador atua como entidade autônoma e toma decisões com respeito ao uso de seus recursos, independente do efeito de sua decisão no resto do sistema. No caso cooperativo, cada processador deve realizar a sua própria porção da tarefa de distribuição, mas todos os processadores trabalham em conjunto para o objetivo comum do sistema. Os algoritmos cooperativos podem ainda ser classificados como ótimos ou sub-ótimos, dependendo da quantidade de informação relacionada com o estado do sistema e com os requisitos de recursos de um processo serem conhecidos.

\section{Adaptável e não-adaptável}

A subclassificação: adaptável e não-adapatável não pertence à classificação hierárquica mas sim à plana [36], porém, devido à sua importância, merece destaque aqui. Um algoritmo de distribuição adaptável é aquele no qual os algoritmos e os parâmetros usados para implementar o algoritmo de distribuição mudam dinamicamente de acordo com o comportamento prévio e atual do sistema. Um exemplo de tal algoritmo adaptável seria considerar vários parâmetros para tomar as decisões de distribuição. Em resposta ao comportamento do sistema, o algoritmo pode começar a ignorar um dos parâmetros ou reduzir a sua importância se ele não estiver provendo alguma informação útil ou até mesmo inconsistente com respeito à mudança do estado do sistema. 


\subsubsection{Exemplos de algoritmos de distribuição de cargas}

Esta seção apresentará alguns algoritmos simples distribuídos e heurísticos de compartilhamento de cargas [28]. Em sistemas distribuídos nos quais as cargas são imprevisíveis, a distribuição de processos entre processadores não pode ser feita determinística ou matematicamente. Para desenvolver algoritmos de compartilhamento de cargas nesse caso, é necessário usar técnicas heurísticas ad-hoc para redistribuir as cargas entre os nós de uma maneira sensata e transparente.

\section{Iniciados pelo remetente}

No caso de algoritmos iniciados pelo remetente, o processo de distribuição de cargas é iniciado pelo nó sobrecarregado (remetente) tentando enviar uma tarefa para um nó menos carregado (destinatário). Eager, Lazowska e Zahorjan [42] propuseram três algoritmos distribuídos simples iniciados pelo remetente na tentativa de implementar compartilhamento de cargas. Nesses algoritmos, cada nó mede sua própria carga quando cria um novo processo e determina se se tornará sobrecarregado (política de transferência). Se sim, ele tenta localizar outro nó do sistema para transferir o novo processo. A diferença entre os algoritmos está em como localizar o nó candidato a destinatário (política de localização).

Política de localização aleatória Aqui o processo é simplesmente transferido para um nó qualquer escolhido aleatoriamente sem que haja troca de informações entre os nós do sistema. Esse processo de transferência pode se provar inútil se o nó destinatário já estiver sobrecarregado. Se este for o caso, o processo recebido é, então, transferido novamente para outro destinatário. Isso pode provocar instabilidade no sistema, pois os nós podem estar gastando a maior parte de seu tempo transferindo processos e não os processando. A instabilidade pode ser resolvida limitando o número de ve- 
zes que um processo pode ser transferido. Embora seja muito simples, este algoritmo provê um ganho substancial em relação ao sistema sem compartilhamento de cargas.

Política de localização com limiar O objetivo desta política de localização é evitar transferências desnecessárias de tarefas da política de localização aleatória. Isso é obtido pesquisando um nó (selecionado aleatoriamente) e determinando se a transferência de uma tarefa para ele faria a sua fila de processos exceder um limiar $T$. Se não, o processo é transferido para o nó selecionado o qual deve aceitar o processo independente de seu estado quando o processo finalmente for transferido. Do contrário, outro nó é selecionado aleatoriamente e o processo de pesquisa se repete. Para manter a sobrecarga baixa, o número de pesquisas realizadas deve ser limitado. Se não for encontrado nenhum destinatário adequado dentro desse limite de pesquisas, o remetente deve executar o processo. Por evitar transferências inúteis de tarefas, a política de localização com limiar provê uma melhora substancial no desempenho em relação à política com localização aleatória.

Política de localização da menor fila A política de localização de menor caminho utiliza mais informação a respeito do estado do sistema do que as outras e tenta escolher o melhor destinatário. Neste caso, um número fixo de nós é selecionado aleatoriamente para obter o comprimento de sua fila de processos. O destinatário será o nó com menor comprimento da fila desde que a sua não exceda o limite $T$ após a transferência do processo. O remetente só executará o processo se o comprimento da fila do destinatário escolhido exceder o limite $T$.

A melhora do desempenho obtido pela política de localização da menor fila não é expressiva em relação à política de localização com limiar, logo a utilização 
de informação mais detalhada não necessariamente melhora de forma significativa o desempenho do sistema.

O problema com algoritmos iniciados pelo remetente é a instabilidade quando a carga do sistema é alta. Isso ocorre porque, neste estado, como é pouco provável encontrar nós ociosos, o remetente tem poucas chances de encontrar um destinatário apropriado. Além disso, a medida que a taxa de criação de processos aumenta, a taxa de procura por um destinatário também aumenta, podendo chegar a um ponto em que o custo de realizar o compartilhamento de cargas é mais alto que os seus benefícios.

\section{Iniciados pelo destinatário}

Nos algoritmos iniciados pelo destinatário, quando um nó se torna ocioso ele tenta obter um processo de um nó mais ocupado. Nesta seção será descrito um algoritmo estudado por Livny e Melman [10] e por Eager, Lazowska e Zahorjan [43]. A política de transferência com limiar nesses algoritmos toma a sua decisão baseada no comprimento da fila de processos e é iniciada quando um processo termina. A partir daí a política de seleção procura um nó aleatoriamente e o testa para determinar se a transferência de uma tarefa faria a sua fila de processos ficar abaixo de um limiar T. Se não, o nó testado transfere um processo. Do contrário, outro nó é selecionado aleatoriamente e o procedimento é repetido até encontrar um remetente adequado ou a quantidade de tentativas exceder um certo limite. Se o número de tentativas exceder tal limite sem encontrar um remetente, o nó destinatário espera até outro processo terminar ou até um período pré-definido antes de reiniciar a atividade de compartilhamento de cargas.

Se o destinatário falhar em encontrar um remetente, a sua potência computacional disponível é perdida até que outro processo seja criado (o que pode não ocorrer durante um longo período de tempo). O problema de perda de desem- 
penho pode ainda ser pior se apenas alguns nós gerarem processos, sendo pouco provável de serem encontrados pelos nós menos carregados.

A vantagem dos algoritmos iniciados pelo destinatário é que eles não provocam instabilidade no sistema, porque quando a carga do sistema for alta, é muito provável o destinatário encontrar um nó sobrecarregado em poucas tentativas. O resultado das tentativas é ainda mais efetivo com aumento da carga do sistema. No entanto, tais algoritmos são mais apropriados para transferências preemptivas de processos do que as não-preemptivas.

\section{Simetricamente iniciado}

Um algoritmo simples iniciado simetricamente pode ser construído combinando as políticas de transferência e de localização usadas nos algoritmos iniciados pelo remetente e pelo destinatário [44]. Ambos os tipos de nós (os ocupados e os ociosos) iniciam a distribuição de processos. Conseqüentemente, estes algoritmos compartilham os benefícios e as desvantagens de ambos os algoritmos iniciados pelo remetente e pelo destinatário.

\section{Simetricamente iniciado adaptável}

A principal causa da instabilidade do algoritmo anterior é a quantidade de pesquisas realizada pelo componente que é iniciado pelo remetente. Em [45] é proposto um algoritmo estável simetricamente iniciado que usa as informações obtidas durante as pesquisas por um parceiro (ao invés de descartá-las, como é feito no algoritmo anterior) para classificar os nós do sistema como remetentelocupado, destinatário/ocioso ou OK (nós com carga controlável). O conhecimento sobre o estado dos nós é mantido em cada nó por uma estrutura de dados composta por três listas: uma de remetentes, uma de destinatários e uma de OK. Cada nó só pode pertencer a uma dessas três listas dependendo do seu estado, e essas listas são 
atualizadas à medida que os remetentes e os destinatários fazem as suas pesquisas por um parceiro. A manutenção dessas listas impõe uma sobrecarga pequena e constante com relação ao número de nós do sistema. Portanto, este algoritmo escala bem em grandes sistemas distribuídos.

\subsection{Resumo do capítulo}

Este capítulo teve como objetivo mostrar como deve ser construído um sistema de balanceamento de carga que, na realidade, é um sistema de distribuição de carga para sistemas distribuídos com características específicas. A distribuição de carga é composta de duas partes: políticas e mecanismos. As políticas são responsáveis por tomar as decisões de distribuição enquanto que os mecanismos, por executálas. O sistema de monitoramento desenvolvido neste trabalho é um mecanismo de informação da carga de sistemas distribuídos. As informações obtidas por esse mecanismo podem ser utilizadas pela política de informação para tomar as decisões mais apropriadas de distribuição de carga. Uma das maiores preocupações da política de informação é com o índice de carga, pois a sua escolha afeta diretamente o desempenho do sistema de compartilhamento de cargas. A maneira como esse índice é obtido pelo sistema de monitoramento de cargas deve ser pensada cuidadosamente, já que a sobrecarga no sistema deve ser pequena.

Outra questão discutida neste capítulo foi a classificação dos algoritmos de escalonamento de processos em sistemas distribuídos. Uma classificação é necessária para comparar e explicar os algoritmos existentes na literatura. No final do capítulo, foram discutidos alguns algoritmos de compartilhamento de cargas: iniciados pelo remetente, iniciados pelo destinatário, simetricamente iniciados e simetricamente iniciados adaptáveis, com o intuito de exemplificar a teoria apresentada e de mostrar onde o sistema de monitoramento de cargas desenvolvido 
neste trabalho pode ser empregado (que é na política de informação). 


\section{CAPÍTULO \\ 4 \\ Sistema de Monitoramento de Cargas}

\subsection{Considerações iniciais}

Como foi salientado nos capítulos anteriores, um sistema de balanceamento ${ }^{1}$ dinâmico de cargas é necessário para obter um bom desempenho em sistemas distribuídos como NOWs, COWs e Grids computacionais. Em sistemas de balanceamento dinâmico de cargas, é essencial a existência de um mecanismo para fornecer as informações de carga dos nós do sistema distribuído à política de informação para tomar as devidas decisões de rebalanceamento de cargas em tempo de execução.

O trabalho desenvolvido neste mestrado foi justamente criar esse mecanismo de informação de carga dos nós de um sistema distribuído. Tal mecanismo, um sistema de monitoramento de cargas, além de obter a carga de cada nó, fornece uma interface de programação para o programador de aplicações paralelas, que também pode ser usado por um sistema de balanceamento dinâmico de cargas.

Com esse sistema de monitoramento de cargas, é possível monitorar qualquer tipo de carga desde que ela seja registrada (será explicado mais tarde como isso pode ser feito, ainda neste capítulo). Inicialmente foram implementados três ti-

\footnotetext{
${ }^{1}$ A partir daqui, o termo balanceamento será sinônimo de compartilhamento discutido no capítulo 3 .
} 
pos de carga: utilização de CPU, de memória e de rede, deixando outros tipos de carga a serem implementados pelo programador da aplicação paralela ou pelo programador do sistema de balanceamento de cargas. Cada tipo de aplicação exige um tipo específico de medida, mas, em geral, utilização de CPU e quantidade de memória disponível já são suficientes para a maioria das aplicações paralelas.

Como afirmado anteriormente, o sistema de monitoramento de cargas foi desenvolvido para ser utilizado em sistemas distribuídos, onde os nós constituintes podem ser arquiteturalmente diferentes e possuírem sistemas operacionais diferentes também (como ocorre em Grids Computacionais). O objetivo deste sistema é dar suporte ao desenvolvimento de aplicações realmente grandes (que exigem alto poder computacional, como aplicações do tipo Seti@ home [46]) e que utilizem recursos computacionais disponíveis da Wold Wide Web, como em Grids computacionais ou mesmo os recursos computacionais disponíveis no mesmo prédio, como em NOWs. Isso pôde ser obtido através do uso da linguagem de programação Java, que garante ser portátil para qualquer plataforma desde que exista uma Máquina Virtual Java (Java Virtual Machine, JVM) para ela. Na próxima seção, a ferramenta Java, que engloba a linguagem, o JVM e a plataforma será apresentada com mais detalhes.

O sistema de monitoramento de cargas foi desenvolvido utilizando-se o modelo cliente/servidor no qual o servidor é responsável por medir a carga do nó e de fornecê-la ao cliente quando solicitado. O sistema foi construído com o uso de RMI, Remote Method Interface [2] que é uma interface API do Java para chamadas de métodos remotos. Em RMI, o servidor é tido como um serviço que é prestado a um cliente e que deve ser registrado a fim de se tornar disponível para os clientes. Na próxima seção, RMI será explicado mais detalhadamente.

Todo o sistema de monitoramento de cargas foi desenvolvido e testado em um cluster de computadores do tipo Beowulf (todos os nós são iguais) com Linux 
Slackware versão 8.1 instalado. Embora Java seja uma linguagem portátil para várias plataformas, a medida de carga computacional não é, pois ela depende do apoio do sistema operacional. Na próxima seção, o sistema utilizado será descrito com maiores detalhes.

\subsection{Ferramentas utilizadas}

\subsubsection{Java}

A ferramenta Java [47] inclui não só uma linguagem de programação mas também uma máquina virtual (JVM) e uma plataforma. A linguagem Java é tida como de alto nível, simples, independente de arquitetura e de sistema operacional, orientada ao objeto com sintaxe similar ao C++ [48], portátil, distribuída, de alto desempenho, interpretada, multithreaded, robusta, dinâmica e segura [49].

Quando um programa Java é compilado, ele é convertido em bytecodes que é uma linguagem de máquina portátil para uma arquitetura conhecida como Máquina Virtual Java, Java Virtual Machine, ou Java VM, ou JVM [47]. O JVM pode ser implementado diretamente em hardware, mas geralmente é implementado na forma de um software que interpreta e executa os bytecodes.

A Máquina Virtual Java, ou interpretador Java, é uma parte fundamental da ferramenta Java. Os programas Java são portáteis só para as plataformas nas quais o interpretador foi portado. Embora os interpretadores não sejam considerados sistemas de alto desempenho, o desempenho do Java VM é considerado bom e vem sendo melhorado gradativamente [47].

A plataforma Java é tão importante quanto a linguagem e o JVM e distinta de ambos. Ela é o conjunto predefinido de classes, que existe em todas as instalações Java; essas classes são disponíveis para uso em qualquer programa Java. A plataforma Java é também conhecida como ambiente Java em tempo de exe- 
cução (Java runtime environment) ou core Java APIs (application programming interfaces). Qualquer classe Java criada pode ser estendida a partir das interfaces dessa plataforma.

Com respeito aos motivos que levaram à escolha da linguagem Java para a implementação do sistema de monitoramento de cargas e dentre as qualidades dessa linguagem destaca-se o fato de ser portátil, um dos objetivos deste trabalho. Pode-se acrescentar também: orientação ao objeto, pela facilidade de associação dos objetos reais aos virtuais; facilidade de comunicação entre os nós do sistema distribuído através de RMI; e facilidade de programação devido à simplicidade da linguagem.

\subsubsection{RMI}

RMI, Remote Method Interface [2] é uma interface designada para chamadas de métodos remotos e projetada para aumentar o nível de abstração de comunicação entre dois computadores (não é necessário se preocupar com sockets, por exemplo). RMI surgiu com o intuito de facilitar a programação em sistemas distribuídos, oferecendo um novo conceito de objetos cujos métodos podem ser chamados remotamente.

Quanto à arquitetura do RMI, foi criado um modelo de objeto distribuído do Java que se integrasse naturalmente à linguagem Java e ao modelo de objetos locais. Os criadores do RMI obtiveram sucesso desenvolvendo esse sistema, pois ele estende a segurança e a robustez da arquitetura do Java para o mundo de computação distribuída.

A arquitetura do RMI é baseada em um importante princípio: a definição do comportamento e a sua implementação são conceitos separados. RMI permite que o código que define o comportamento e o que define a sua implementação permaneçam separados e rodem em diferentes JVMs. Isso se ajusta bem nas ne- 


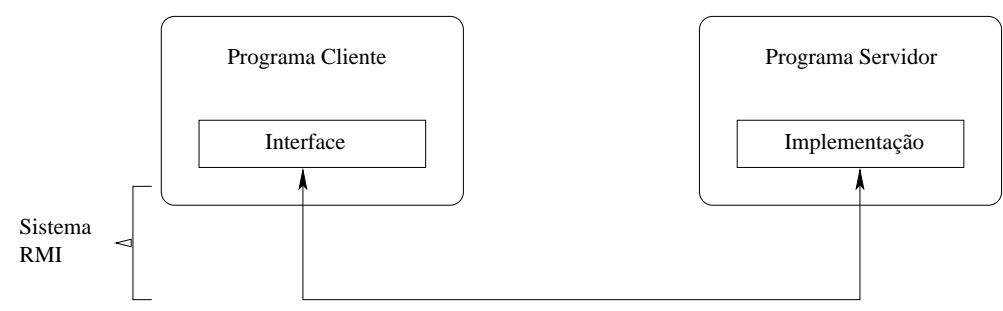

Figura 4.1: Diagrama mostrando a separação entre interface e implementação Fonte [2].

cessidades de um sistema distribuído em que os clientes estão preocupados apenas com a definição do serviço e os servidores em prover esse serviço.

Em RMI, a definição de um serviço remoto dá-se usando uma interface Java e a implementação desse serviço é feita usando uma classe. Assim, para entender RMI é necessário lembrar que interfaces (em Java, a interface não contém código executável) definem comportamento e classes definem implementação. A figura 4.1 ilustra essa separação.

RMI suporta duas classes que implementam a mesma interface. A primeira é a implementação do comportamento e é executada no servidor. A segunda atua como um proxy para um serviço remoto e é executada no cliente. Tal distinção é mostrada na figura 4.2. Um programa cliente realiza chamadas de métodos no objeto do proxy, RMI envia o pedido para o JVM remoto e o encaminha para a implementação. Qualquer valor retornado pela implementação é enviado de volta para o proxy e depois para o programa cliente.

Enquanto a ferramenta Java é portátil e provê facilidades de programação, entre outras vantagens, o RMI fornece o que falta para a programação em sistemas distribuídos: o uso de objetos remotos com comunicação num nível mais alto de abstração. Assim, o uso de ambos: a ferramenta Java e o RMI, foi muito importante para o desenvolvimento de sistema de monitoramento de cargas em sistemas distribuídos heterogêneos. 


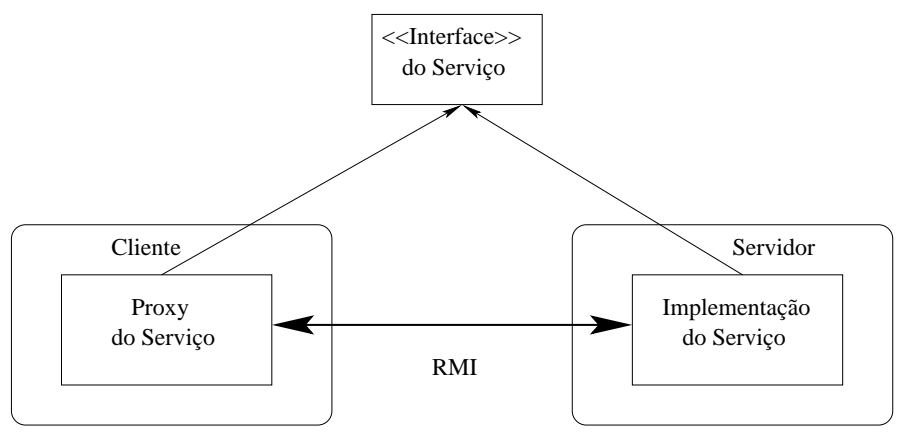

Figura 4.2: Diagrama mostrando a distinção entre proxy e implementação do serviço. Fonte [2].

\subsubsection{Sistema utilizado para desenvolvimento e teste}

O sistema paralelo utilizado para o desenvolvimento e teste do sistema de monitoramento foi um cluster de 16 computadores do tipo Beowulf [6], onde todos os nós são iguais (com exceção do nó principal, ou de acesso, que possui três placas de rede) e possuem processador K6-III 450MHz, $256 \mathrm{MB}$ de memória SDRAM, disco rígido de $10 \mathrm{~GB}$ e duas placas de rede ethernet, uma de $10 \mathrm{Mb} / \mathrm{s}$ e uma de $100 \mathrm{Mb} / \mathrm{s}$, e sistema operacional Linux Slackware versão 8.1. A topologia de rede é do tipo estrela [50], com um switch de $100 \mathrm{Mb} / \mathrm{s}$ e um hub de $10 \mathrm{Mb} / \mathrm{s}$ no centro. A figura 4.3 mostra uma foto do cluster utilizado.

Embora o sistema de monitoramento de cargas tenha sido projetado para sistemas distribuídos heterogêneos, o uso do cluster ${ }^{2}$ permitiu analisar o quanto de sobrecarga o sistema desenvolvido impõe na execução de programas paralelos. E, para simular um sistema distribuído heterogêneo, foi colocada carga em alguns nós, desbalanceando a carga geral do sistema.

Outro aspecto importante a ser mencionado é que o sistema operacional dita como a carga de cada nó deve ser obtida, pois cada um possui um jeito próprio

\footnotetext{
${ }^{2}$ Aqui, cluster é sinônimo de um sistema distribuído homogêneo onde apenas uma aplicação paralela é executada por vez.
} 


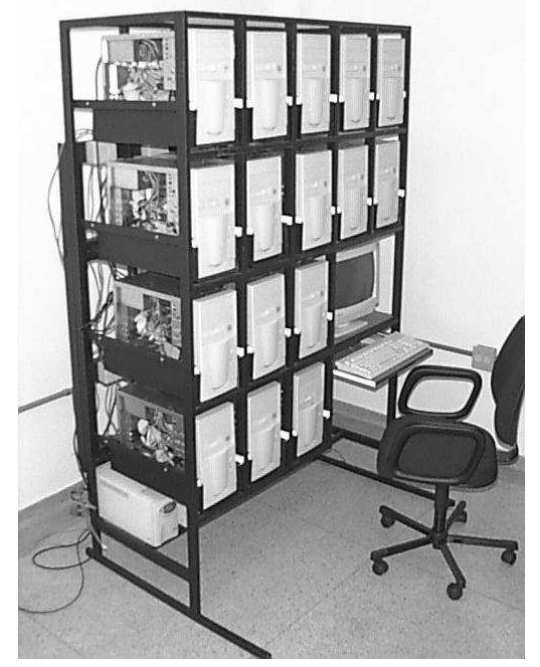

Figura 4.3: Cluster de computadores do Laboratório de Processamento Paralelo Aplicado, utilizado para desenvolver e testar o sistema de monitoramento de cargas.

para medir a carga. Por exemplo, em sistemas Unix em geral todas as informações do computador são guardadas em arquivos e atualizadas periodicamente; assim, para saber como os recursos desse computador estão sendo utilizados, basta ler os arquivos que guardam essas informações. No Slackware, as informações de uso de CPU podem ser obtidas através do arquivo/proc/stat; as de uso de memória, em /proc/meminfo; e as de tráfego de rede, em /proc/net/dev. Isso demonstra que a obtenção de carga é dependente de plataforma, sendo necessário implementá-la para cada tipo de plataforma.

\subsection{Descrição do sistema de monitoramento}

O sistema de monitoramento de cargas é constituído de duas partes: um cliente e um servidor. O servidor é o programa que fornece o serviço de informação de carga do nó que o hospeda. O cliente é o que acessa esse serviço e pede 
a informação de carga. O cliente pode ser uma central de informações a qual deve ser projetada de acordo com o algoritmo de balanceamento de cargas que se queira usar. Por exemplo, se o algoritmo de balanceamento dinâmico de cargas for centralizado, a central de informação de cargas deve ficar no mesmo nó que toma as decisões de balanceamento e pedir a informação de carga de todos os nós, mas se o algoritmo for distribuído, a central pode ficar em alguns nós ou em todos e cada central pode requerer a informação de carga de apenas alguns nós e não de todos, o que tornaria o algoritmo mais tolerante a falhas e sem gargalos.

Já o servidor é um objeto cujos métodos podem ser chamados remotamente pela central (objeto RMI). Para cada tipo de carga há um servidor (ou serviço) associado. Para incluir um novo tipo de medida, o programador tem de implementar as interfaces LoadIndex e Resource para o tipo de carga desejado e registrar o serviço. A primeira representa o índice de carga e a segunda é a interface para objetos remotos cujo método mede a carga e retorna um objeto LoadIndex. A figura 4.4 ilustra o uso dessas interfaces.

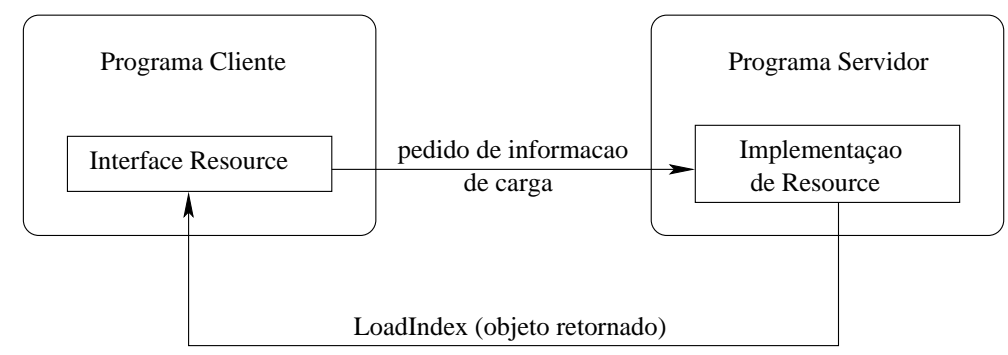

Figura 4.4: Esquema mostrando como funciona o sistema de monitoramento de cargas. Observe que o objeto retornado pela implementação de uma sub-classe da interface Resource é da classe base LoadIndex.

\subsubsection{Interface LoadIndex}

A interface LoadIndex é definida pelo código: 


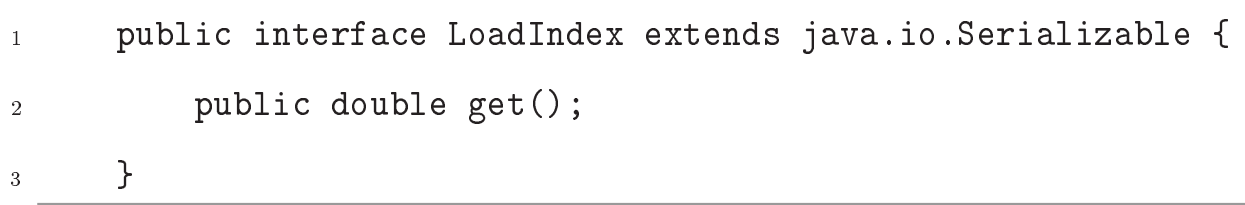

Essa interface define que cada objeto derivado represente o índice de carga para um determinado tipo de medida. O método get () é o método de acesso a esse índice cujo valor varia entre 0.0 e 1.0, ou seja, entre totalmente ocioso e totalmente ocupado. Embora a maioria dos sistemas de distribuição de cargas utilizam um único índice de carga para representar o estado de um dado nó, este sistema de monitoramento define índices de carga individuais de maneira que o programador da aplicação paralela ou do sistema de distribuição de cargas escolha os que melhor lhe convier. No entanto, também é possível a definição de uma classe derivada dessa interface que englobe várias medidas e retorne um único índice desde que a interface Resource seja devidamente implementada.

As classes que implementam essa interface são os tipos de carga os quais se deseja medir. Neste trabalho, as classes implementadas foram: CPULoadIndex, MemLoadIndex e NetLoadIndex que representam os índices de carga de CPU, de memória e de rede, respectivamente. MemLoadIndex é um pouco diferente das demais e, além de representar o índice de carga de memória total (RAM $+S$ wap ${ }^{3}$ ), é composta de outras subclasses LoadIndex: RamLoadIndex, que representa o índice de carga de memória física (RAM), e SwapLoadIndex, o índice de carga de memória virtual (Swap). Além do método get (), MemLoadIndex possui dois outros métodos: um de acesso a objetos da classe RamLoadIndex e outro de acesso a objetos da classe SwapLoadIndex.

Com respeito ao código, ela estende java.io. Serializable porque as classes derivadas precisam ser convertidas em sequiências de bytes para serem transportadas pela rede.

${ }^{3}$ RAM (Random Access Memory, memória de acesso aleatório) é a memória física do computador. Já Swap é uma parte do disco rígido utilizada pelo sistema operacional para complementar a memória física do computador. 


\subsubsection{Interface Resource}

A interface Resource é definida pelo código:

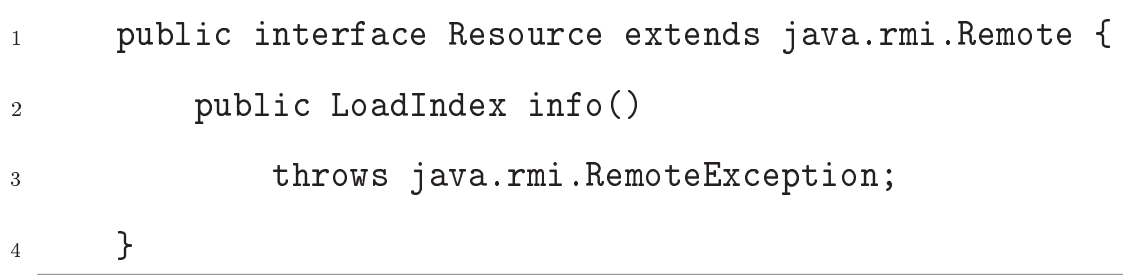

Essa interface define o comportamento que o objeto da classe derivada deve possuir, ou seja, retornar um objeto da interface LoadIndex quando receber uma mensagem info(). Esse comportamento deve ser implementado para o tipo de medida desejada de carga através de uma sub-classe de Resource. Na implementação das classes derivadas de Resource, é necessário garantir que o objeto de retorno seja de uma sub-classe de LoadIndex.

O cliente para um determinado tipo de medida de carga só precisa da definição dessa interface para poder realizar a chamada do método info() e receber o índice de carga correspondente ao pedido efetuado. No entanto, o método info() retorna apenas objetos da classe base LoadIndex, e o cliente terá que converter o objeto recebido para o tipo correspondente.

O servidor para um certo tipo de medida, por outro lado, precisa da implementação dessa interface em uma sub-classe, de maneira a poder prover o serviço correspondente. A seguir, serão apresentadas três sub-classes da interface Resource desenvolvidas neste trabalho de mestrado para o sistema Linux: CPUResourceImpl, MemResourceImpl e NetResourceImpl.

\section{CPUResourceImpl}

É a classe que implementa a medida de carga de CPU, que é realizada pelo método info() o qual retorna o índice de carga de CPU. A medida de carga de CPU é realizada através 
da leitura do arquivo/proc/stat. A figura 4.5 mostra um trecho desse arquivo (que é a única parte importante para os propósitos deste trabalho). Após a palavra cpu da primeira linha, os números seguintes são: user, nice (modo user com baixa prioridade), system e other. Esses números representam a quantidade de jiffies ${ }^{4}$ gasta em cada estado desde que o computador foi ligado, logo esses números sempre aumentam. Cada um tem um significado diferente: user representa o tanto de jiffies gasto pelo usuário; nice, o que foi gasto no modo user com baixa prioridade; system, o que foi gasto pelo sistema operacional; e other, o que não foi gasto com nenhum dos anteriores (tempo em que a CPU ficou ociosa).

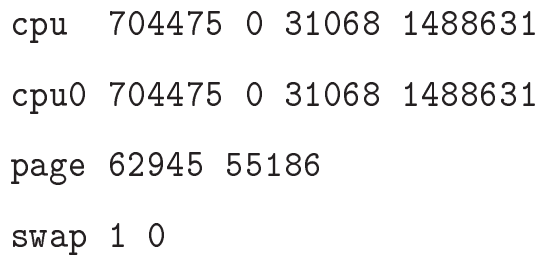

Figura 4.5: Trecho que mostra o início do arquivo /proc/stat.

Como o sistema operacional atualiza esse arquivo de 10 em 10 milisegundos, é suficiente fazer duas leituras consecutivas desse arquivo com intervalo maior do que $10 \mathrm{mi}$ lisegundos para obter a quantidade de jiffies gasta em cada estado do sistema num certo instante de tempo e calcular o índice de carga de CPU. Uma maneira de fazer esse cálculo é:

$$
C P U L \text { LadIndex }=1.0-\frac{O}{U+N+S+O}
$$

onde: CPULoadIndex é o índice de carga de CPU; $O$ é a diferença de jiffies do estado other medida nesse intervalo de tempo; $U, N$ e $S$ é o mesmo para user, nice e system, respectivamente. Após calcular esse índice, um objeto da classe CPULoadIndex é construído com esse valor e retornado pelo método info() ao cliente que requisitou o serviço de medida de carga de CPU.

\footnotetext{
${ }^{4} 1$ jiffy é igual a 10 milisegundos [51].
} 


\section{MemResourceImpl}

É a classe que implementa a medida de carga de memória a qual é realizada através da leitura do arquivo/proc/meminfo. Os objetos dessa classe calculam três índices de carga: um de memória RAM, RamLoadIndex, um de memória $S$ wap, SwapLoadIndex e um da memória total (RAM $+S$ wap), MemLoadIndex. Para cálculo desses índices, é necessário só uma leitura do arquivo /proc/meminfo. Na figura 4.6, é mostrado um trecho desse arquivo.

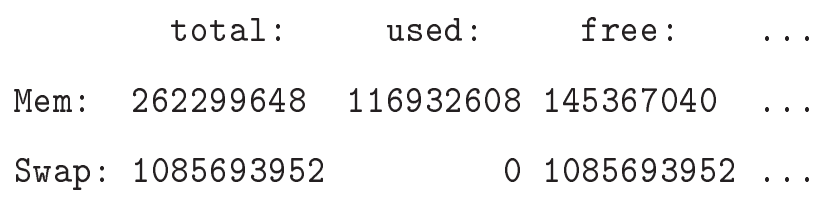

Figura 4.6: Trecho do arquivo/proc/meminfo que mostra a quantidade total e usada de memória RAM (no arquivo, Mem é a memória RAM) e Swap em bytes.

Aqui, o cálculo do índice de carga de memória é mais fácil. Nos três casos, o índice é obtido dividindo-se a quantidade de memória usada pelo total. No caso da memória total (RAM + Swap), o índice é obtido somando-se a quantidade de memória RAM e a de Swap usadas e dividindo o resultado pela soma do total das duas. Após o cálculo desses índices, constrói-se um objeto classe MemLoadIndex, e o método info() o retorna para o cliente que solicitou o serviço de medida de carga de memória.

Embora MemLoadIndex represente o índice de carga de memória total do sistema, é preferível, em geral, usar o de carga de memória RAM, RamLoadIndex, porque a memória Swap é bem mais lenta.

\section{NetResourceImpl}

Essa classe implementa a medida de carga de rede que é realizada através da leitura do arquivo /proc/net/dev. Um trecho desse arquivo pode ser visto na figura 4.7. Os “...” representam a parte desse arquivo que não é importante para a medida de carga 
de rede. Os dados importante são: a quantidade de bytes recebidos e a quantidade de bytes transmitidos por uma dada interface de rede que pode ser: eth0, eth1 e eth2.

\begin{tabular}{rrrrrrrl} 
Inter- | & \multicolumn{2}{c}{ Receive } & \multicolumn{3}{c}{ | Transmit } \\
face | bytes packets & $\ldots$ & | bytes & packets & $\ldots$ \\
10: 1852196 & 18675 & $\ldots$ & 1852196 & 18675 & $\ldots$ \\
eth0:15306096 & 110036 & $\ldots$ & 102817704 & 160434 & $\ldots$ \\
eth1: 3022820 & 20586 & $\ldots$ & 1285216 & 16793 & $\ldots$ \\
eth2: 3198330 & 36850 & $\ldots$ & 2513430 & 14839 & $\ldots$
\end{tabular}

Figura 4.7: Trecho do arquivo/proc/net/dev o qual mostra a quantidade de bytes transmitido e recebido por uma dada interface de rede desde que o computador foi ligado.

O cálculo do índice de carga de rede segue o mesmo raciocínio do de CPU: lê-se $\mathrm{o}$ arquivo / proc/net/dev duas vezes e se determina quantos bytes foram recebidos e quantos foram transmitidos numa certa interface de rede e num certo intervalo de tempo. Somando-se essas quantidades, dividindo o resultado pelo intervalo de tempo e, depois pela largura de banda máxima, obtém-se o índice de carga de rede. Em seguida, com esse índice, é construído um objeto da classe NetLoadIndex que é retornado pelo método

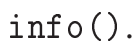

O mesmo raciocínio é aplicado para obter a largura de banda máxima para uma dada interface de rede. Foram criados dois programas que são executados em diferentes nós e ficam trocando dados entre si. Cada um é composto por duas partes (duas threads): uma que fica só enviando dados e outra que fica só recebendo, e cada thread é um loop que não pára de enviar dados ou receber. Após colocar esses dois programas para executar em nós diferentes, medem-se e somam-se a quantidade de bytes transmitidos e recebidos pela interface de rede usada. O resultado dessa soma dividido pelo intervalo de tempo usado para medir essas quantidades é a largura de banda máxima conseguida pela interface de rede utilizada. É importante mencionar que o processo de obtenção da largura de banda máxima é necessário apenas uma vez para a interface de rede que será utilizada pelos computadores do sistema distribuído. 


\subsubsection{Servidores e clientes}

Os servidores e os clientes ${ }^{5}$ constituem a base para o funcionamento do sistema que monitora cargas em sistemas distribuídos. O servidor é a aplicação que é executada em todos os nós do sistema distribuído e que fica aguardando pelas requisições dos clientes. A medição de um determinado tipo de carga é realizada pelo objeto de uma classe derivada da classe Resource, e a única tarefa do servidor consiste em criar esse objeto permitindoo ser acessado pelos clientes.

Para exemplificar o sistema de monitoramento de cargas, serão apresentados o servidor e o cliente responsáveis pela medição de carga de CPU. O trecho mais importante do código do servidor de medição de carga de CPU é mostrado abaixo:

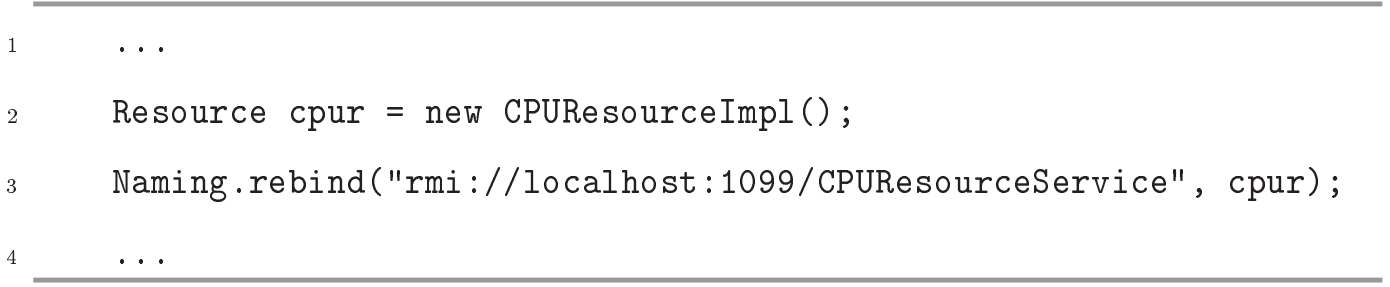

A linha 2 desse código diz que cpur é um objeto da classe Resource cuja implementação é dada por CPUResourceImpl. A linha 3 indica que o objeto cpur é associado ao endereço rmi://localhost: 1099/CPUResourceService, onde localhost significa o computador que hospeda o servidor e 1099 (porta padrão usada pelo RMI) é a porta onde o serviço CPUResourceService fica aguardando conexões. Desta maneira, a única tarefa do servidor é criar um objeto acessível remotamente e ficar esperando por pedidos de clientes; toda a parte de medição de um determinado tipo de carga é deixada para a implementação desse objeto, que, no caso de carga de CPU, é um objeto da classe CPUResource Impl.

\footnotetext{
${ }^{5} \mathrm{O}$ cliente não precisa ser só uma aplicação que requisita um serviço de um servidor como ocorre com o modelo usual de cliente/servidor. No sistema de monitoramento, o termo "cliente" se refere a parte do código de uma central de informações ou de uma aplicação paralela que pede um determinado serviço dos servidores de informação de carga.
} 
Enquanto que o servidor somente cria um objeto para um determinado tipo de medida e o torna acessível aos clientes, o cliente também cria o mesmo tipo de objeto mas que não é local, sendo necessário especificar onde se localiza a implementação desse objeto. Assim, quando o cliente chamar um método desse objeto, essa chamada será encaminhada ao servidor especificado e o cliente aguardará pelo término desse método. A seguir, é exibido um trecho do cliente para pedidos de informação de carga de CPU:

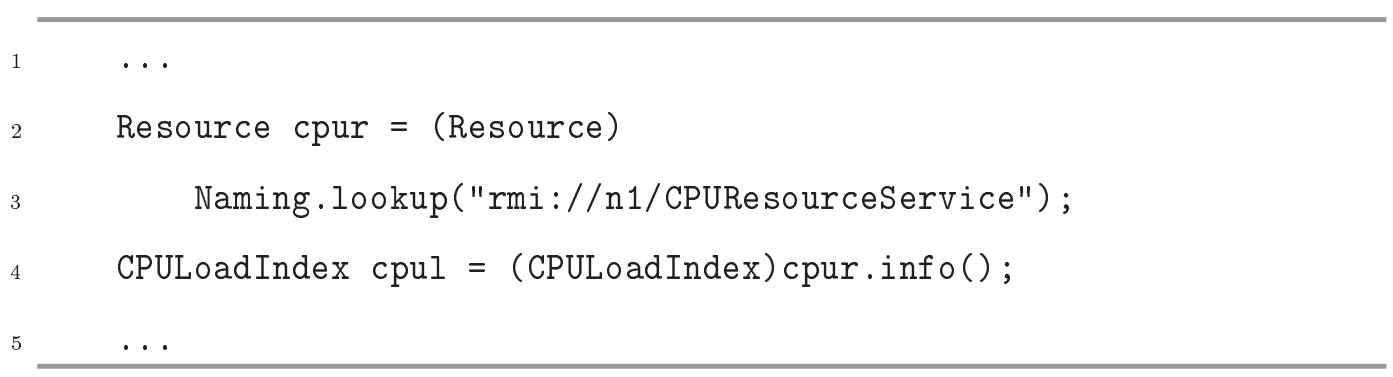

No cliente, também é definido um objeto da classe Resource (linha 2), todavia este objeto é remoto, como mostra a linha 3. Tal linha indica que o objeto cpur não é local mas sim remoto e que deve ser procurado no endereço rmi ://n1/CPUResourceService, onde $\mathrm{n} 1$ é o endereço do nó em que está o objeto remoto, ou seja, é o endereço do computador do qual se quer saber o seu índice de carga de CPU. Após encontrar o servidor, o cliente chama o método info() para obter o índice de carga do nó desejado, como é mostrado na linha 4. Também nessa linha, nota-se que é necessário uma conversão do objeto de retorno do método info(): LoadIndex para o tipo desejado: CPULoadIndex que é guardado pelo objeto cpul.

A fim de que o sistema de monitoramento funcione ainda falta registrar os servidores nos nós do sistema distribuído para os clientes saberem como encontrar os servidores. Isso é realizado ao executar o comando rmiregistry port, onde port é o número da porta em que o servidor aguarda conexões (se não for especificada nenhuma porta, o RMI utiliza a porta padrão 1099). Com o rmiregistry rodando, é só colocar os servidores para serem executados. Diz-se, então que o servidor foi registrado no RMI e que já está disponível para receber conexões. Quando o cliente for executado, ele procurará pelo 
computador onde se encontra o seu objeto remoto, "perguntará" ao RMI qual é o servidor que fornece o serviço que ele está pedindo e, se encontrado, conectará diretamente ao servidor e, depois, fará a chamada do método remoto info() para saber a carga do servidor.

\subsubsection{Inclusão de novos tipos de medidas}

Se o programador desejar incluir uma nova medida de carga, ele terá que criar uma subclasse de LoadIndex e outra de Resource, as aplicações cliente e servidor, e registrar o serviço correspondente ao novo tipo de medida. A sub-classe de LoadIndex precisará conter as informações necessárias para determinar o índice de carga desejado. A subclasse de Resource deverá implementar o método info() para medir a esse tipo de carga, construir o objeto da sub-classe anterior e retorná-lo. O cliente e o servidor deverão ser criados com sintaxe similar à discutida na subseção 4.3.3. Para exemplificar como seria a inclusão de novos tipos de medidas, veja os exemplos abaixo:

Tamanho da fila de processos: O método get () da sub-classe de LoadIndex, ao invés de retornar um valor entre 0 e 1 , pode ser implementado de modo a devolver um número que indique a quantidade de processos na fila de processos do computador que está sendo analisado. Para implementar a classe derivada da interface Resource, será necessário descobrir como o sistema operacional guarda a informação da fila de processos e implementar o método info() para obter essa informação, montar o objeto da sub-classe de LoadIndex desenvolvida e retorná-lo. Por fim, criar o servidor e o cliente de maneira análoga à descrita na subseção 4.3.3 e registrar o serviço que mede esse novo tipo de carga.

Dinâmica molecular: Neste problema de física estatística, poderia ser criado um sistema de medida de carga o qual trabalhasse em conjunto com a aplicação paralela que resolvesse este problema. A carga poderia ser a quantidade de partículas destinada a cada processador do sistema distribuído. Desta maneira, a sub-classe de LoadIndex representaria a quantidade de partículas designada a cada processador, 
e a sub-classe de Resource seria uma parte da aplicação paralela que determinaria a quantidade de partículas presente em cada processador.

\subsection{Resumo do capítulo}

Este capítulo mostrou como foi construído o sistema de monitoramento de cargas, apresentou as ferramentas utilizadas justificando-as e explicou o funcionamento do sistema.

O sistema de monitoramento de cargas é constituído por duas partes: o serviço, responsável por informar um determinado tipo de carga do nó que o hospeda e a central de informação, responsável por pedir essa informação. No próximo capítulo, será mostrado como essa central pode ser implementada num problema específico. 


\section{CAPÍTULO \\ 5 \\ Testes e resultados}

\subsection{Considerações iniciais}

Neste capítulo, pretende-se mostrar a eficiência do sistema de monitoramento de cargas desenvolvido neste trabalho de mestrado. Para testar tal sistema foram construídas duas aplicações: uma que utiliza o sistema e realiza compartilhamento dinâmico de cargas e outra que não, e realiza compartilhamento de carga estático.

No desenvolvimento dessas aplicações, os conceitos discutidos no capítulo 3 foram empregados. A primeira aplicação utiliza um algoritmo de distribuição de cargas global, dinâmico, distribuído, cooperativo, não-adaptativo e iniciado pelo destinatário. Já a segunda utiliza um algoritmo simples de distribuição de cargas global e estático.

O computador paralelo utilizado para testar essas aplicações foi o cluster de computadores descrito na subseção 4.2.3. Mesmo não sendo um bom exemplo de sistema distribuído em que os poderes computacionais dos nós constituintes variam drasticamente, ele permitiu analisar a sobrecarga imposta pelo sistema de monitoramento ao realizar o compartilhamento de cargas. Além disso, para simular um sistema distribuído com desbalanceamento de carga foram colocadas aplicações para serem executadas em alguns nós. 


\subsection{Problema abordado}

As aplicações foram desenvolvidas para resolver um problema clássico do xadrez: encontrar o número de soluções do problema do passeio do cavalo em um tabuleiro de tamanho arbitrário. Este problema pertence a uma classe de problemas que, apesar de simples na formulação, envolve números tão grande que muito tempo ou material é necessário para resolvê-los, tornando-os quase impossíveis de serem solucionados manualmente durante uma vida humana.

O "grãos de trigo em um tabuleiro de xadrez", descrito por Gamow [52] é um dos mais simples e clássicos problemas desse tipo. O problema consiste em se determinar quantos grãos de trigo são necessários para preencher o tabuleiro de xadrez da seguinte forma: 1 grão na primeira casa, 2 na segunda, 4 na terceira, 8 na quarta, e assim por diante. Cada casa recebe o dobro da quantidade da casa anterior até todas as 64 casas do tabuleiro estarem completas. Gamow estima que seriam necessários 2000 anos de toda a produção mundial para preencher o tabuleiro.

\begin{tabular}{|l|l|l|l|l|}
\hline & 3 & & 2 & \\
\hline 4 & & & & 1 \\
\hline & & 4 & & \\
\hline 5 & & & & 8 \\
\hline & 6 & & 7 & \\
\hline
\end{tabular}

Figura 5.1: Movimentos possíveis do cavalo em um tabuleiro de xadrez.

O problema do passeio do cavalo, diferente do problema dos grão de trigo, envolve muito tempo para resolvê-lo e não material. Este problema consiste em encontrar todas as soluções de: o cavalo percorrer todo o tabuleiro de xadrez e visitar cada casa apenas uma vez, partindo de todas as casas do tabuleiro. Os movimentos possíveis do cavalo são os permitidos pelas regras usuais do xadrez: na forma de "L", duas casas em uma direção e uma na direção perpendicular à das outras. A figura 5.1 mostra os movimentos possíveis 
do cavalo.

Em um tabuleiro $8 \times 8$, há 64 casas iniciais para o começo do passeio do cavalo. Para cada casa, é necessário testar 8 movimentos possíveis. Cada vez que um movimento é executado, é preciso testar outros 8 movimentos, depois outros 8 e assim por diante, até que todas as 64 casas sejam visitadas. $\mathrm{Na} 63^{a}$ casa, 8 movimentos devem ser considerados. $\mathrm{Na} 62^{a}$ casa, $8^{2}$ movimentos devem ser testados. Em geral, na $n$-ésima casa, o número de movimentos a ser testado é $8^{(64-n)}$, com um número significativamente menor de movimentos executáveis. Se o problema do passeio do cavalo fosse simples de ser resolvido como o de grãos de trigo, a determinação de todas as possíveis soluções para uma dada casa inicial seria descrita por uma soma de uma série geométrica: $8+8^{2}+8^{3}+\ldots+8^{63}$ ou, aproximadamente, $8^{64}$ testes, que não é um número pequeno! De fato, só são necessários 8 novos testes se é possível executar todos os movimentos, portanto o número de testes requeridos é um pouco menor.

Para um ser humano com um tabuleiro de xadrez, um cavalo, um bloco de papel para anotar os movimentos, com um método sistemático e mãos rápidas, seria necessário tanto tempo para encontrar uma única solução que seria quase impossível resolver esse problema manualmente em uma vida inteira. Veja duas soluções na figura 5.2.

\begin{tabular}{|l|l|l|l|l|l|l|l|}
\hline 35 & 40 & 47 & 44 & 61 & 08 & 15 & 12 \\
\hline 46 & 43 & 36 & 41 & 14 & 11 & 62 & 09 \\
\hline 39 & 34 & 45 & 48 & 07 & 60 & 13 & 16 \\
\hline 50 & 55 & 42 & 37 & 22 & 17 & 10 & 63 \\
\hline 33 & 38 & 49 & 54 & 59 & 06 & 23 & 18 \\
\hline 56 & 51 & 28 & 31 & 26 & 21 & 4 & 03 \\
\hline 29 & 32 & 53 & 58 & 05 & 02 & 19 & 24 \\
\hline 52 & 57 & 30 & 27 & 20 & 25 & 04 & 01 \\
\hline
\end{tabular}

\begin{tabular}{|l|l|l|l|l|l|l|l|}
\hline 32 & 35 & 30 & 25 & 08 & 05 & 50 & 55 \\
\hline 29 & 24 & 33 & 36 & 51 & 56 & 07 & 04 \\
\hline 34 & 31 & 26 & 09 & 06 & 49 & 54 & 57 \\
\hline 23 & 28 & 37 & 12 & 01 & 52 & 03 & 48 \\
\hline 38 & 13 & 22 & 27 & 10 & 47 & 58 & 53 \\
\hline 19 & 16 & 11 & 4 & 61 & 02 & 43 & 46 \\
\hline 14 & 39 & 18 & 21 & 44 & 41 & 62 & 59 \\
\hline 17 & 20 & 15 & 40 & 63 & 60 & 45 & 42 \\
\hline
\end{tabular}

Figura 5.2: Duas soluções possíveis para o problema do passeio do cavalo em um tabuleiro $8 \times 8$. Os números acima indicam o número do pulo do cavalo, onde "01" é a casa onde o cavalo inicia o seu passeio e "64" (a casa que o cavalo está ocupando) é a última. 
A fim de tornar o problema mais rápido de ser resolvido, ao invés de usar o tabuleiro usual do xadrez de $8 \times 8$ casas, as aplicações desenvolvidas para resolver esse problema usaram um tabuleiro $M \times N$ casas, com $M$ e $N$ menores que 8 .

\subsection{Solução seqüencial}

Na resolução seqüencial, denominada de CavSeq, as soluções são encontradas uma de cada vez sendo necessário testar todos os caminhos até que não seja possível continuar o percurso do cavalo (no próximo movimento, só são encontradas casas já visitadas) ou até achar uma solução.

O tabuleiro $M \times N$ é representado por uma matriz e cada casa é iniciada com o valor 0 (não visitada). A casa onde o cavalo inicia o seu percurso é marcada com o valor 1. A próxima casa para onde o cavalo salta é marcada com o valor 2 , e assim por diante. Portanto, no passo $n$, a casa ocupada pelo cavalo é marcada com o valor $n$, se ela ainda não foi visitada. O caminho percorrido pelo cavalo só será solução se no passo $M \cdot N$ houver uma casa ainda não visitada acessível ao cavalo, ou seja, todas as casas são visitadas.

À medida que o cavalo passeia pelo tabuleiro, várias são as opções para continuar seu percurso. Desta maneira, os caminhos percorridos pelo cavalo são ramos de uma árvore que se constrói para representá-los. Cada nó dessa árvore é uma casa que o cavalo pode visitar. Um exemplo pode ser observado na figura 5.3.

Mesmo apresentando ramos pequenos (último nó do ramo não possui casas para onde o cavalo possa saltar, porque elas já devem ter sido visitadas), encontrar todas as soluções (ramos com altura igual a $M \cdot N$ ) é uma tarefa muito custosa e exige muito tempo de computação. Além de ter que encontrar todos os ramos dessa árvore para achar as soluções partindo de uma casa inicial, é necessário fazer o mesmo para as outras casas do tabuleiro, ou seja, para encontrar todas as soluções desse problema é necessário encontrar todos os ramos com altura $M \cdot N$ das $M \cdot N$ árvores. 

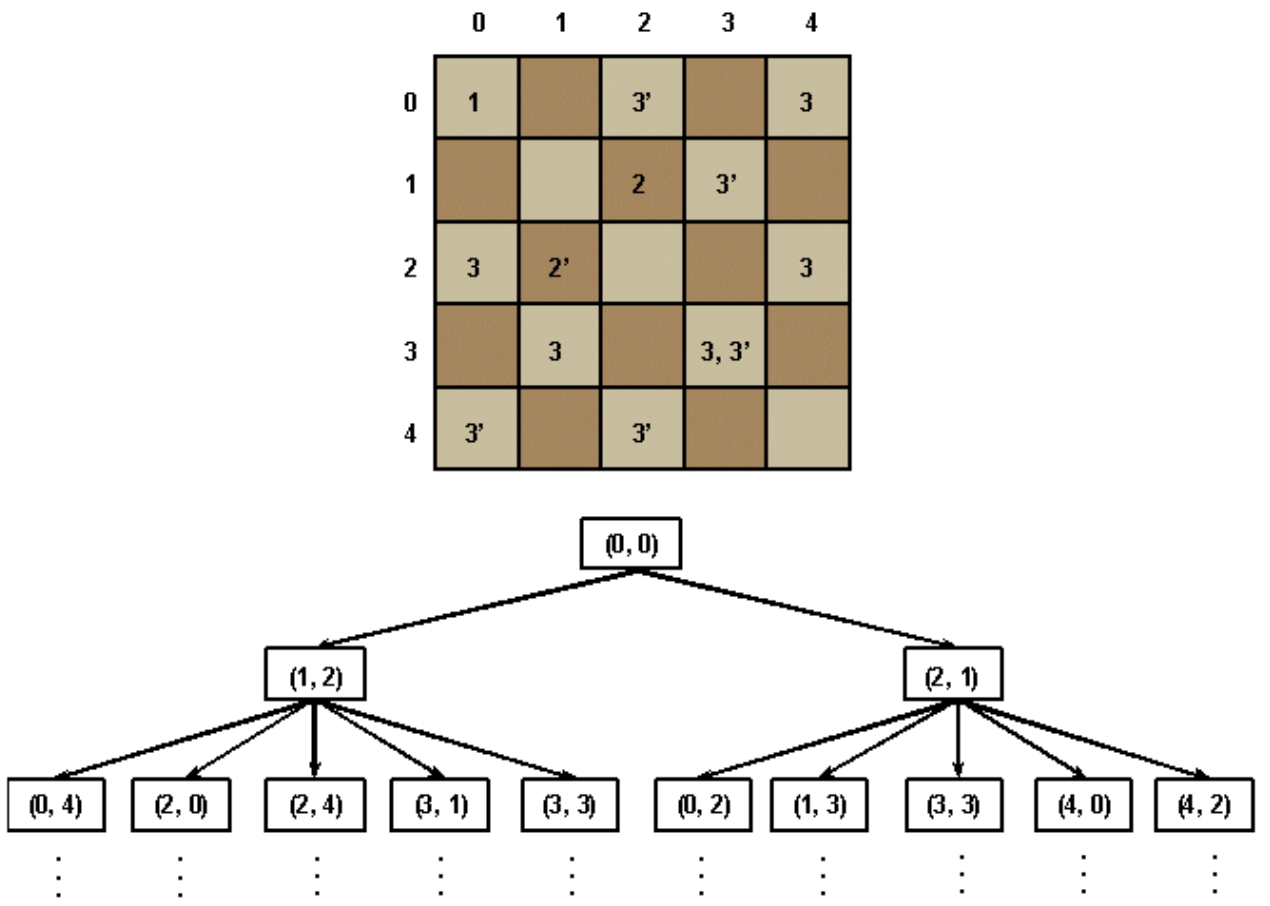

Figura 5.3: Árvore formada no percurso do cavalo.

\subsection{Solução paralela}

Como cada casa inicial representa uma árvore distinta das outras, as soluções para uma dada casa inicial podem ser encontradas por um único computador, logo vários computadores podem ser usados para resolver esse problema mais rapidamente, desde que o número total de casas do tabuleiro onde o cavalo inicia seu passeio seja dividido entre os computadores disponíveis. Esta foi a forma utilizada para paralelizar este problema, embora não seja a melhor solução paralela por não ser escalável. Se o número de computadores for maior que o tamanho do tabuleiro, alguns computadores ficarão inutilizados. No entanto, a intenção do desenvolvimento da solução paralela para este problema foi testar o sistema de monitoramento de cargas desenvolvido neste trabalho de mestrado e não achar a melhor solução.

As próximas subseções descreverão as duas aplicações desenvolvidas para encontrar as soluções para o problema do passeio do cavalo. 


\subsubsection{Compartilhamento estático de cargas}

A aplicação que implementa o compartilhamento de cargas estático divide igualmente a quantidade de casas iniciais entre os computadores. Se a divisão do tamanho do tabuleiro pela quantidade de computadores não for exata, alguns ficam com uma casa a mais que os outros. Esta solução, embora simples, é suficiente para implementar um algoritmo de compartilhamento de cargas em cluster de computadores em que todos os nós são iguais.

Esta aplicação foi desenvolvida usando RMI e é denominada de CavParEst. Há um cliente, ou o gerente, que distribui as casas iniciais entre os nós usando o esquema descrito no parágrafo anterior e espera pelos resultados. Os servidores, ou trabalhadores, são responsáveis por realizar a procura de soluções dadas as casas iniciais recebidas do gerente e por retornar a quantidade de soluções encontradas. A aplicação termina quando o último resultado for recebido pelo gerente.

\subsubsection{Compartilhamento dinâmico de cargas}

Aqui, procurou-se desenvolver uma aplicação que utilizasse o sistema de monitoramento de cargas e realizasse compartilhamento dinâmico de cargas. A unidade de carga (processamento) utilizada pelo algoritmo de compartilhamento foi a casa inicial, onde o cavalo inicia o seu passeio.

Também houve uma certa preocupação com o uso dos conceitos discutidos no capítulo 3. A aplicação desenvolvida neste caso utiliza um algoritmo global, dinâmico, distribuído, cooperativo, não-adaptativo e iniciado pelo destinatário e é denominada de CavParDin. A seguir, cada característica desse algoritmo será explicada:

Global: é um algoritmo global porque a carga é distribuída entre todos os nós do computador paralelo;

Dinâmico: pois o compartilhamento de cargas é realizado em tempo de execução;

Distribuído: porque não existe uma unidade central de redistribuição de cargas. Isso é feito por todos os nós do computador paralelo; 
Cooperativo: porque os nós tentam minimizar as diferenças de carga entre eles para aumentar o desempenho geral;

Não-adaptativo: pois o sistema de compartilhamento de cargas não varia diante da mudança de estado do computador paralelo;

Iniciado pelo destinatário: porque o compartilhamento de cargas é iniciado quando um nó se torna ocioso e pede carga (casas iniciais) dos outros nós.

Com respeito às políticas utilizadas, pode-se dizer que:

- A política de transferência utilizada é a de limiar. Embora ela não seja explícita, ela é de limiar porque, quando se acabam as casas iniciais, o computador se torna ocioso, ou seja, a sua carga de CPU fica abaixo de um certo limiar.

- A política de seleção seleciona quaisquer casas iniciais restantes, pois não existe distinção entre elas.

- A política de localização procura por nós cujo índice de CPU exceda um certo limiar para pedir a transferência de casas iniciais. Essa pesquisa é realizada investigando todos os nós do sistema distribuído. Uma solução que sobrecarregasse menos seria pesquisar apenas alguns vizinhos, mas como o número de nós do cluster era pequeno, todos foram pesquisados.

- A política de informação utiliza a coleta de informação por demanda, ou seja, só é utilizada quando necessária. Quando um nó se torna ocioso, a política de informação se encarrega de procurar por nós ocupados através do uso do mecanismo de informação, o sistema de monitoramento de carga de CPU, e retorna os nós ocupados para a política de localização.

A aplicação desenvolvida aqui também utiliza um gerente e trabalhadores da mesma forma descrita na subseção anterior. A única diferença está na construção dos trabalhadores. O trabalhador, além de calcular as soluções dadas as suas casas iniciais, também 
pede outras casas iniciais para os outros trabalhadores quando as suas acabarem, e divide as suas quando outro trabalhador requisita carga.

Os trabalhadores são compostos por três partes: uma que procura as soluções dada uma casa inicial, uma que gerencia uma pilha de casas iniciais e outra que pede novas casas iniciais quando a pilha fica vazia. Quando um trabalhador esvazia a sua pilha de casas iniciais, a parte que pede novas casas iniciais procura por computadores ocupados (utilizando o sistema de monitoramento de carga de CPU descrito no capítulo 4) e os guarda em uma lista. A partir dessa lista, essa parte do trabalhador ocioso tenta descobrir quantas casas iniciais sobrando há no primeiro computador da lista. Se for maior que 1 , então o computador ocupado transfere metade de suas casas iniciais restantes para o computador ocioso (se nessa divisão sobrar uma casa, ela é também transferida para o nó ocioso). Se não houver casas iniciais restantes, então o nó ocioso repete esse processo para o próximo nó da lista de ocupados; se também não houver casas iniciais restantes nesse nó, ele tenta o próximo da lista, e assim por diante, até conseguir carga de algum nó ocupado ou chegar no final da sua lista de nós ocupados. Se ele não conseguir nenhuma casa inicial, ele termina a sua execução.

A parte do servidor que gerencia a pilha de casas iniciais é também a que fica aguardando por pedidos de carga. Quando outro trabalhador pede casas iniciais para ele, essa parte verifica o tamanho da sua pilha e transfere metade de suas casas iniciais (mais uma se a divisão não for exata) para o nó que fez o pedido.

Quando a aplicação CavParDin é iniciada, o gerente o qual é executado no nó principal ou de acesso ao cluster distribui igualmente as casas iniciais do tabuleiro a ser calculado entre todos os nós do cluster, inclusive o nó principal.

Em seguida, cada trabalhador recebe a sua quantidade de casas iniciais, preenche a sua pilha e começa o cálculo de soluções retirando uma casa da pilha. Ao término desse cálculo, ele retira outra casa e reinicia o cálculo de soluções. Esse processo é repetido até se acabarem todas as casas iniciais da sua pilha. Quando isso ocorre, o trabalhador com a sua pilha vazia efetua uma busca pelos nós ocupados utilizando o sistema de monitoramento de carga de CPU, como descrito. Com a sua pilha preenchida novamente o 
trabalhador repete o processo de cálculo de soluções. Os trabalhadores só descansarão quando se acabarem as casas iniciais de sua pilha e não encontrarem nenhum nó ocupado ou, quando encontrarem, os nós ocupados não possuírem nenhuma casa inicial a transferir.

\subsection{Resultados}

Foram realizados dois testes: um em que o tabuleiro era de $5 \times 5$ e outro em que o tabuleiro era de $5 \times 6$. Os testes objetivaram obter os tempos de execução e os speedups das aplicações CavParEst e CavParDin e compará-los, variando-se o número de nós e medindo o tempo de execução de cada aplicação. Com os tempos de execução das aplicações com relação ao número de processadores e o tempo de execução do CavSeq, e com a expressão 2.1, o speedup foi calculado para cada caso.

\subsubsection{Primeiro teste: tabuleiro de $5 \times 5$}

Neste primeiro teste, foram encontradas 1.728 soluções e, além de usar o cluster, foi simulado um sistema distribuído desbalanceado utilizando o mesmo cluster com outras aplicações sendo executadas.

\section{Cluster balanceado}

Apenas com o cluster, sem nenhuma outra aplicação sendo executada ao mesmo tempo, a aplicação seqüencial, CavSeq levou $T_{0}=149,8$ segundos. Nessa mesma condição, os resultados obtidos com a execução das aplicações paralelas podem ser encontrados na tabela 5.1. Entretanto, nestes casos, há uma outra aplicação rodando no cluster que também faz parte das aplicações paralelas: o gerente, o qual só é executado no nó principal.

Na tabela 5.1, é possível notar que em alguns casos o tempo de execução não varia muito com o acréscimo de mais processadores. Por exemplo, entre $P=9$ e $P=11$, $T_{P} \simeq 28,5 \mathrm{~s}$. Isso ocorre porque na divisão das casas iniciais do tabuleiro de $5 \times 5$ 
Tabela 5.1: Tempo e speedup obtidos com a execução das aplicações paralelas no cluster balanceado. Tabuleiro solucionado de $5 \times 5$. $P$ representa o número de processadores.

\begin{tabular}{|c|c|c|c|c|}
\hline & \multicolumn{2}{|c|}{ Tempo (s) } & \multicolumn{2}{c|}{ Speedup } \\
\hline$P$ & CavParEst & CavParDin & CavParEst & CavParDin \\
\hline 2 & 94,971 & 90,938 & 1,577 & 1,647 \\
\hline 3 & 66,683 & 65,263 & 2,246 & 2,295 \\
\hline 4 & 56,057 & 52,886 & 2,672 & 2,833 \\
\hline 5 & 44,636 & 46,934 & 3,356 & 3,192 \\
\hline 6 & 37,766 & 39,509 & 3,967 & 3,792 \\
\hline 7 & 31,933 & 33,863 & 4,691 & 4,424 \\
\hline 8 & 29,777 & 31,413 & 5,031 & 4,769 \\
\hline 9 & 28,586 & 29,755 & 5,240 & 5,034 \\
\hline 10 & 28,487 & 28,013 & 5,259 & 5,347 \\
\hline 11 & 28,527 & 26,993 & 5,251 & 5,550 \\
\hline 12 & 21,477 & 22,941 & 6,975 & 6,530 \\
\hline 13 & 20,199 & 22,616 & 7,416 & 6,624 \\
\hline 14 & 20,263 & 22,769 & 7,393 & 6,579 \\
\hline 15 & 19,723 & 22,354 & 7,595 & 6,701 \\
\hline 16 & 19,543 & 21,724 & 7,665 & 6,895 \\
\hline
\end{tabular}

(25 casas iniciais), alguns processadores recebem 3 casas iniciais e os outros recebe 2 , e o tempo de execução total é dado pelo tempo de execução de 3 casas iniciais. Os processadores com mais casas iniciais são os limitantes no tempo de execução total. O mesmo ocorre entre $P=13$ e $P=16$, em que alguns processadores recebem 2 casas iniciais e os outros apenas 1.

Para $P=8$, ocorre um fato inusitado que não é erro de medida como se poderia pensar. Com $P=8$, seria esperado que o tempo de execução total fosse dado pela soma do tempo de cálculo das soluções para 4 casas iniciais, como ocorre com $P=7$, pois há um processador com 4 casas iniciais. No entanto não é o que se observa, $T_{8}=29,777 \mathrm{~s}$ e não $T_{8} \simeq T_{7}=31,933 \mathrm{~s}$. Isso ocorre por causa da variação do tempo de cálculo das soluções para cada casa inicial.

Como encontrar as soluções para cada casa inicial é o mesmo que determinar todos os ramos da árvore gerada (ver figura 5.3), o tempo de cálculo é diretamente proporcional ao 
número de nós nos ramos dessa árvore, logo, quanto maiores os ramos, mais demorado é o cálculo das soluções. E, como cada casa inicial gera uma árvore diferente, os tempos de cálculo de soluções para cada casa inicial também são diferentes. No caso de um tabuleiro de $5 \times 5$, os tempos de cálculo para cada casa inicial variam entre: $2,5 \mathrm{~s}, 4,0 \mathrm{~s}, 5,6 \mathrm{~s}$, 6,8 s e 7,1 s. No caso de $P=8$, certamente o processador que recebeu 4 casas iniciais, recebeu casas cujos tempos de cálculo eram pequenos, assim se explica o seu tempo de execução ser bem menor do que o esperado.

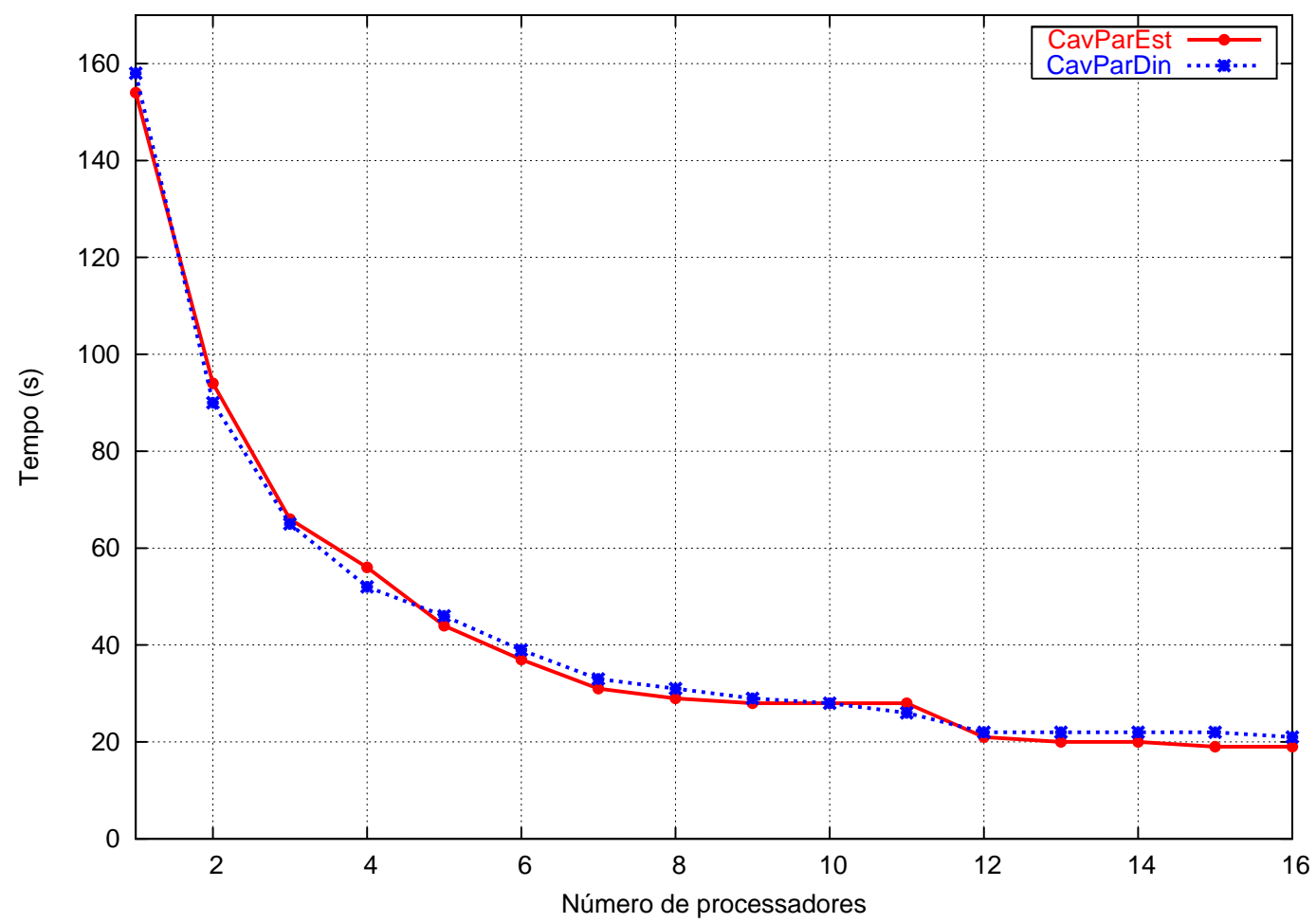

Figura 5.4: Gráfico mostrando o tempo de execução das aplicações paralelas em um cluster balanceado. Tabuleiro solucionado de $5 \times 5$.

A fim de facilitar a visualização dos dados da tabela 5.1, foram construídos dois gráficos: figuras 5.4 e 5.5. O primeiro mostra como o tempo de execução das aplicações paralelas varia com o aumento do número de processadores. Nesse gráfico, percebe-se que CavParEst é mais rápido na maioria dos casos do que CavParDin. Isso se deve ao fato de que a granularidade (tempo de cálculo das soluções para uma dada casa ini- 
cial) é grande e, portanto, não é fácil atingir uma boa distribuição de cargas. Assim, o CavParDin tende a piorar a distribuição de cargas, embora apenas levemente. Um ponto positivo do CavParDin é que a sobrecarga no sistema distribuído é baixa, pois a diferença de tempo de execução das aplicações paralelas é pequena. Em cinco casos, ele até ganha do CavParEst, $P=2, P=3, P=4, P=10$ e $P=11$.

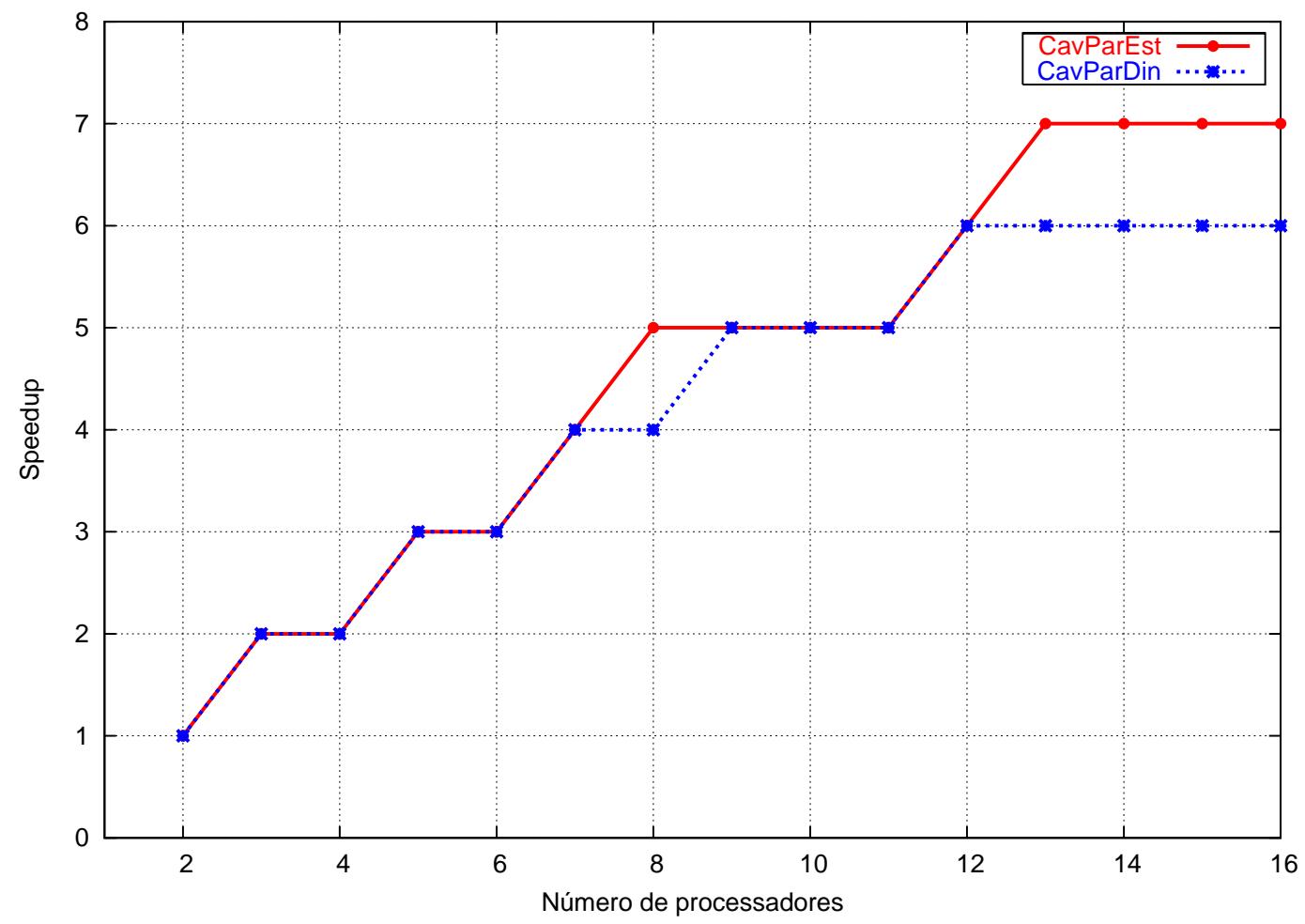

Figura 5.5: Gráfico em que é mostrado o speedup das aplicações paralelas em um cluster balanceado. Tabuleiro solucionado de $5 \times 5$.

O segundo gráfico mostra como o speedup dessas aplicações varia com o número de processadores. Nesse gráfico, verificam-se certos patamares que ocorrem porque, mesmo variando o número de processadores utilizado, o processador que receber o maior número de casas iniciais, receberá a mesma quantidade em todos os casos nessas regiões. A partir desse gráfico, nota-se que o acréscimo de mais processadores não necessariamente reduz o tempo de execução total dessas aplicação, quando o número de processadores se encontra nessas regiões de patamares. Outro ponto importante é que se aumentar o 
Tabela 5.2: Tempo obtido com a execução das aplicações paralelas no cluster desbalanceado. Tabuleiro solucionado de $5 \times 5$.

\begin{tabular}{|c|c|c|c|c|}
\hline & \multicolumn{2}{|c|}{ Tempo (s) } & \multicolumn{2}{c|}{ Speedup } \\
\hline$P$ & CavParEst & CavParDin & CavParEst & CavParDin \\
\hline 2 & 232,575 & 129,47 & 0,644 & 1,157 \\
\hline 3 & 161,163 & 106,864 & 0,929 & 1,402 \\
\hline 4 & 132,523 & 75,764 & 1,130 & 1,977 \\
\hline 5 & 107,439 & 76,506 & 1,394 & 1,958 \\
\hline 6 & 87,972 & 58,848 & 1,703 & 2,546 \\
\hline 7 & 76,272 & 56,836 & 1,964 & 2,636 \\
\hline 8 & 68,969 & 56,666 & 2,172 & 2,644 \\
\hline 9 & 68,146 & 57,495 & 2,198 & 2,605 \\
\hline 10 & 68,332 & 45,588 & 2,192 & 3,286 \\
\hline 11 & 68,225 & 45,993 & 2,196 & 3,257 \\
\hline 12 & 45,705 & 44,049 & 3,278 & 3,401 \\
\hline 13 & 45,715 & 44,641 & 3,277 & 3,356 \\
\hline 14 & 45,477 & 45,454 & 3,294 & 3,296 \\
\hline 15 & 45,83 & 44,526 & 3,269 & 3,364 \\
\hline 16 & 45,714 & 45,279 & 3,277 & 3,308 \\
\hline
\end{tabular}

número de processadores acima do número de casas do tabuleiro, não haverá ganho no tempo de processamento. No entanto, não era intenção construir um programa eficiente mas sim aplicações para testar o sistema de monitoramento desenvolvido neste trabalho de mestrado.

\section{Cluster desbalanceado}

Aqui, foi testado como as duas aplicações paralelas se comportam quando o cluster está desbalanceado, ou seja, quando há aplicações sendo executadas ao mesmo tempo em que os testes foram realizados. Isso foi feito para simular um ambiente como o de NOWs ou de Grids computacionais. O cluster foi desbalanceado colocando-se a aplicação burnK6 (uma aplicação de uso intensivo de CPU) para ser executada em metade dos nós. Este teste foi realizado da seguinte forma: para um certo $P$, número de processadores, foram colocados dois burnK6 em $P / 2$ processadores se $P$ for par, ou $(P+1) / 2$ se $P$ for 


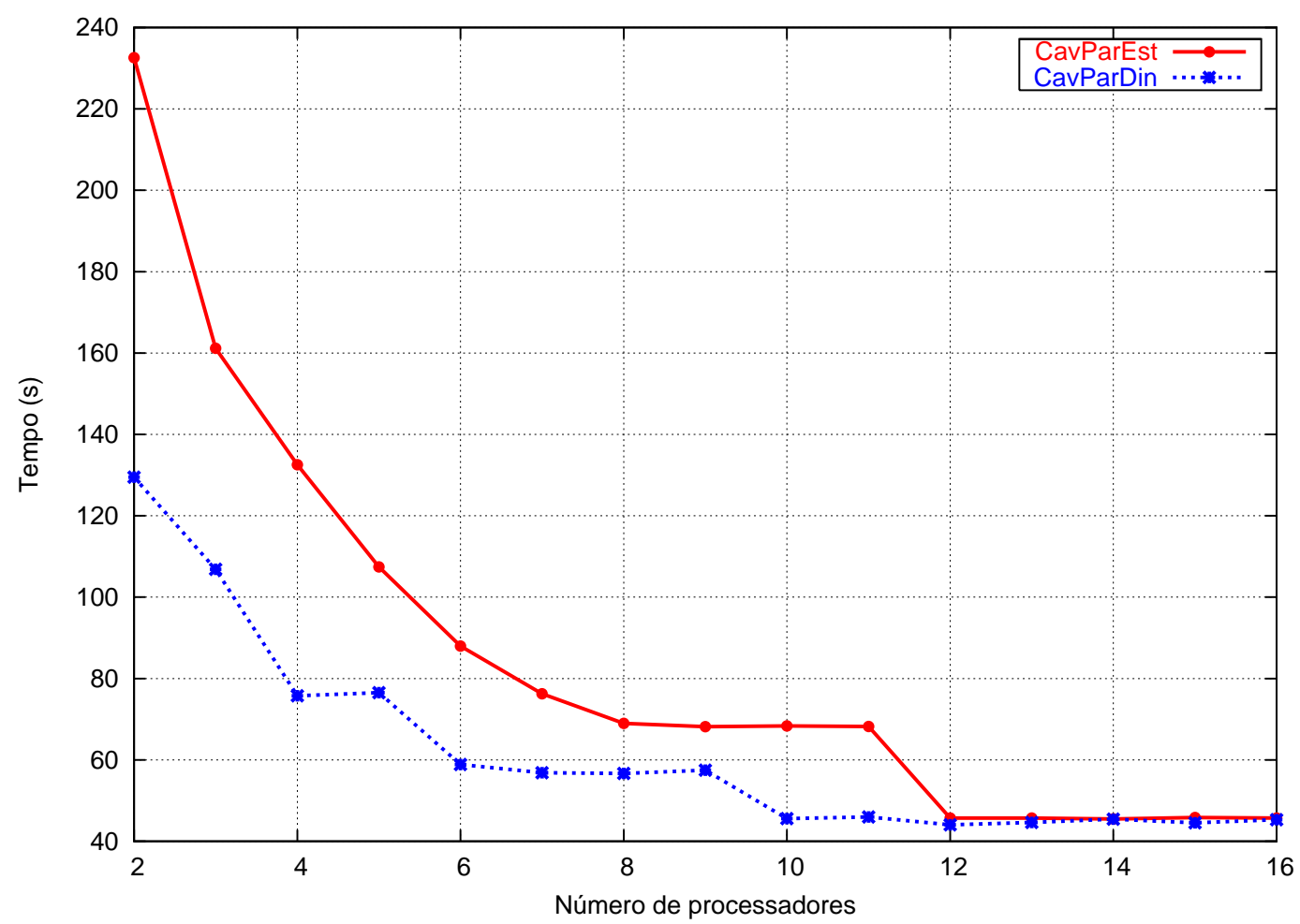

Figura 5.6: Gráfico mostrando o tempo de execução das aplicações paralelas em um cluster desbalanceado. Tabuleiro solucionado de $5 \times 5$.

ímpar. Desta maneira, nos nós onde houver burnK6s rodando, a aplicação paralela que estiver sendo executada, terá apenas aproximadamente $1 / 3$ da CPU disponível, enquanto nos outros, ela terá quase $100 \%$ da CPU. Os resultados obtidos neste teste podem ser encontrados na tabela 5.2. Esses dados são mais bem visualizados nas figuras 5.6 e 5.7.

Na figura 5.6, nota-se que o CavParDin é mais rápido do que o CavParEst em todos os casos, indicando que, em sistemas distribuídos desbalanceados, o sistema de compartilhamento dinâmico de cargas é melhor do que o estático. Na tabela 5.2, percebe-se outro fato inusitado: para $P=2$ e $P=3$, CavParEst é mais lento do que CavSeq, $T_{2}=232,575 \mathrm{~s} \mathrm{e} T_{3}=161,163 \mathrm{~s}$ contra $T_{0}=149,8 \mathrm{~s}$. Isso ocorre porque $T_{0}$ é obtido com CavSeq sendo executado em um processador livre de outras aplicações enquanto que nos outros casos há aplicações (burnK6) rodando ao mesmo tempo e muitas casas iniciais para cada processador (para $P=2,13$ casas iniciais para um processador e 12 para o 
outro; para $P=3,9$ para o primeiro, 8 para o segundo e 8 para o terceiro).

Na figura 5.7, há algumas oscilações na curva do CavParDin. Isso é fruto da dificuldade do sistema de compartilhamento de cargas dinâmico do CavParDin em redistribuir a carga eficientemente entre os nós do cluster já que a granularidade é grande. Outra conseqüência disso é que, em alguns casos, aumentar $P$ não melhora o speedup (por exemplo, o speedup com 14 processadores é menor do que com 13).

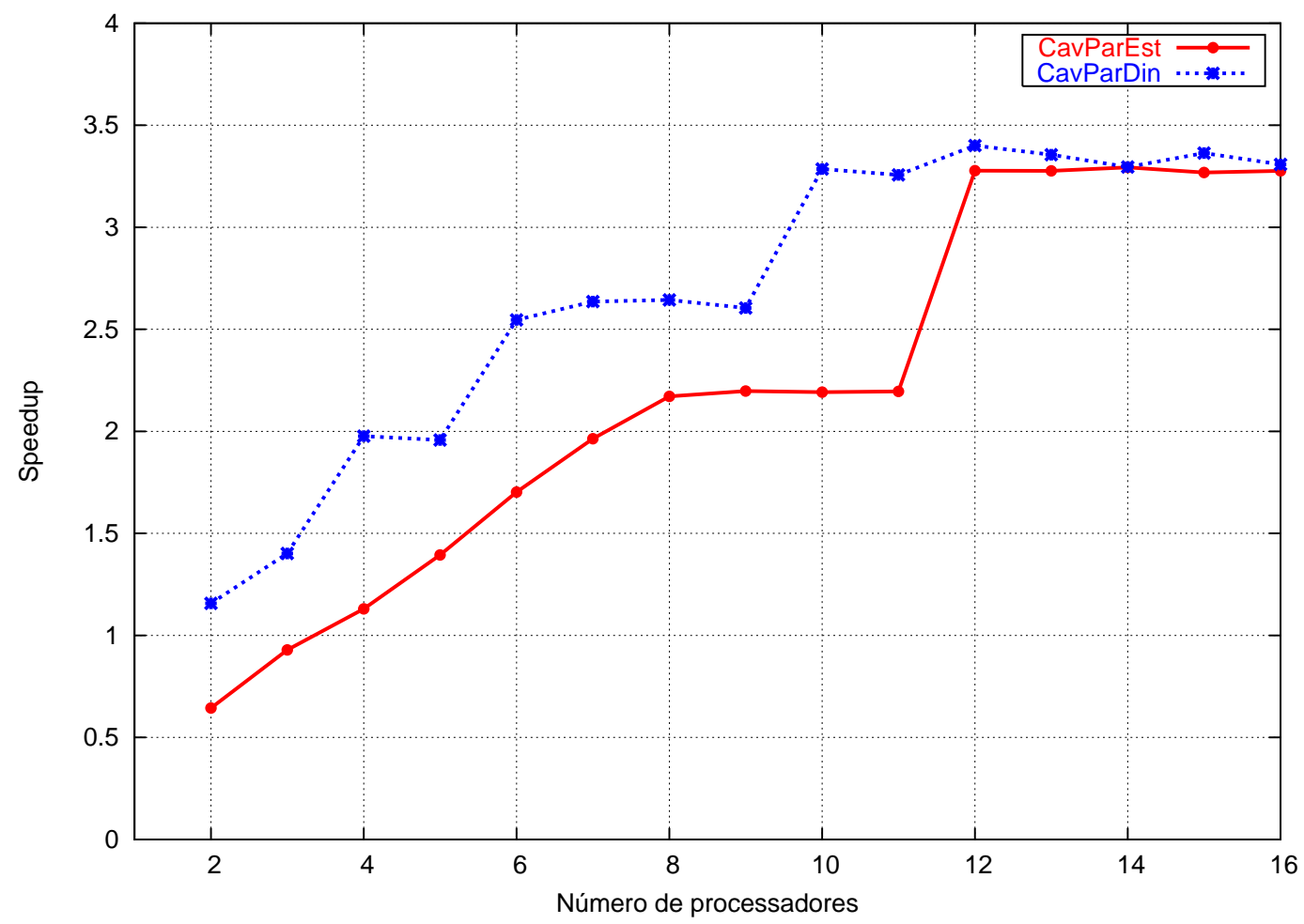

Figura 5.7: Gráfico em que é mostrado o speedup das aplicações paralelas em um cluster desbalanceado. Tabuleiro solucionado de $5 \times 5$.

\subsubsection{Segundo teste: tabuleiro de $5 \times 6$}

Este teste foi realizado apenas com o cluster balanceado (sem nenhuma outra aplicação rodando). Neste teste, foram encontradas 37.568 soluções e CavSeq levou $T_{0}=168,5 \mathrm{~min}$ para terminar. Já os tempos de execução das aplicações paralelas dependentes de $P$ podem ser visualizados na tabela 5.3, assim como os respectivos speedups. 
Tabela 5.3: Tempo e speedup obtidos com a execução das aplicações paralelas no cluster balanceado. Tabuleiro solucionado de $5 \times 6$.

\begin{tabular}{|c|c|c|c|c|}
\hline & \multicolumn{2}{|c|}{ Tempo (min) } & \multicolumn{2}{c|}{ Speedup } \\
\hline$P$ & CavParEst & CavParDin & CavParEst & CavParDin \\
\hline 2 & 105,404 & 95,174 & 1,598 & 1,795 \\
\hline 3 & 75,092 & 68,694 & 2,244 & 2,487 \\
\hline 4 & 59,573 & 53,547 & 2,828 & 3,191 \\
\hline 5 & 51,906 & 49,418 & 3,246 & 3,458 \\
\hline 6 & 41,804 & 42,738 & 4,03 & 3,998 \\
\hline 7 & 34,33 & 35,053 & 4,908 & 4,875 \\
\hline 8 & 33,015 & 28,769 & 5,103 & 5,939 \\
\hline 9 & 33,062 & 25,871 & 5,096 & 6,605 \\
\hline 10 & 25,318 & 25,915 & 6,654 & 6,593 \\
\hline 11 & 24,281 & 22,429 & 6,939 & 7,618 \\
\hline 12 & 24,255 & 21,567 & 6,946 & 7,923 \\
\hline 13 & 24,278 & 21,281 & 6,939 & 8,029 \\
\hline 14 & 24,287 & 18,082 & 6,937 & 9,45 \\
\hline 15 & 17,78 & 18,216 & 9,476 & 9,381 \\
\hline 16 & 17,705 & 18,095 & 9,516 & 9,443 \\
\hline
\end{tabular}

O primeiro ponto a ser discutido é o tempo de execução dessas aplicações que é muito maior do que quando o tabuleiro era de $5 \times 5$. Por exemplo, CavSeq leva $149,8 \mathrm{~s} \mathrm{com}$ o tabuleiro de $5 \times 5$ e 168, 5 min com tabuleiro de $5 \times 6$. Aqui não só houve aumento na quantidade de casas mas também na granularidade. Enquanto que no primeiro caso leva-se em média 6 s para encontrar as soluções para cada casa inicial, no segundo caso leva-se em média 5,5 min. Um aumento considerável na granularidade a ser distribuída pelas aplicações paralelas. Esse é o motivo pelo qual as aplicações paralelas possuem um speedup melhor com tabuleiro de $5 \times 6$ do que com tabuleiro de $5 \times 5$ em quase todos os casos (veja as tabelas 5.1 e 5.3), pois há mais trabalho para cada processador.

Além do aumento na granularidade média, houve um crescimento da diferença dos tempos de cálculo para cada casa inicial. Esse é um dos motivos pelo qual CavParDin é melhor do que CavParEst em quase todos os casos. Outro motivo é a existência de mais casas iniciais a serem distribuídas entre cada processador. Deste modo, CavParDin 
consegue balancear melhor a carga do sistema distribuído.

As figuras 5.8 e 5.9 mostram dois gráficos construídos a partir dos dados da tabela 5.3. Na figura 5.8, nota-se que CavParDin é mais rápido do que CavParEst mas não muito, pois a granularidade média é alta e não é possível distribuir tão bem a carga no sistema distribuído. Também se conclui que a sobrecarga imposta no sistema distribuído pelo compartilhamento dinâmico de cargas do CavParDin é baixa.

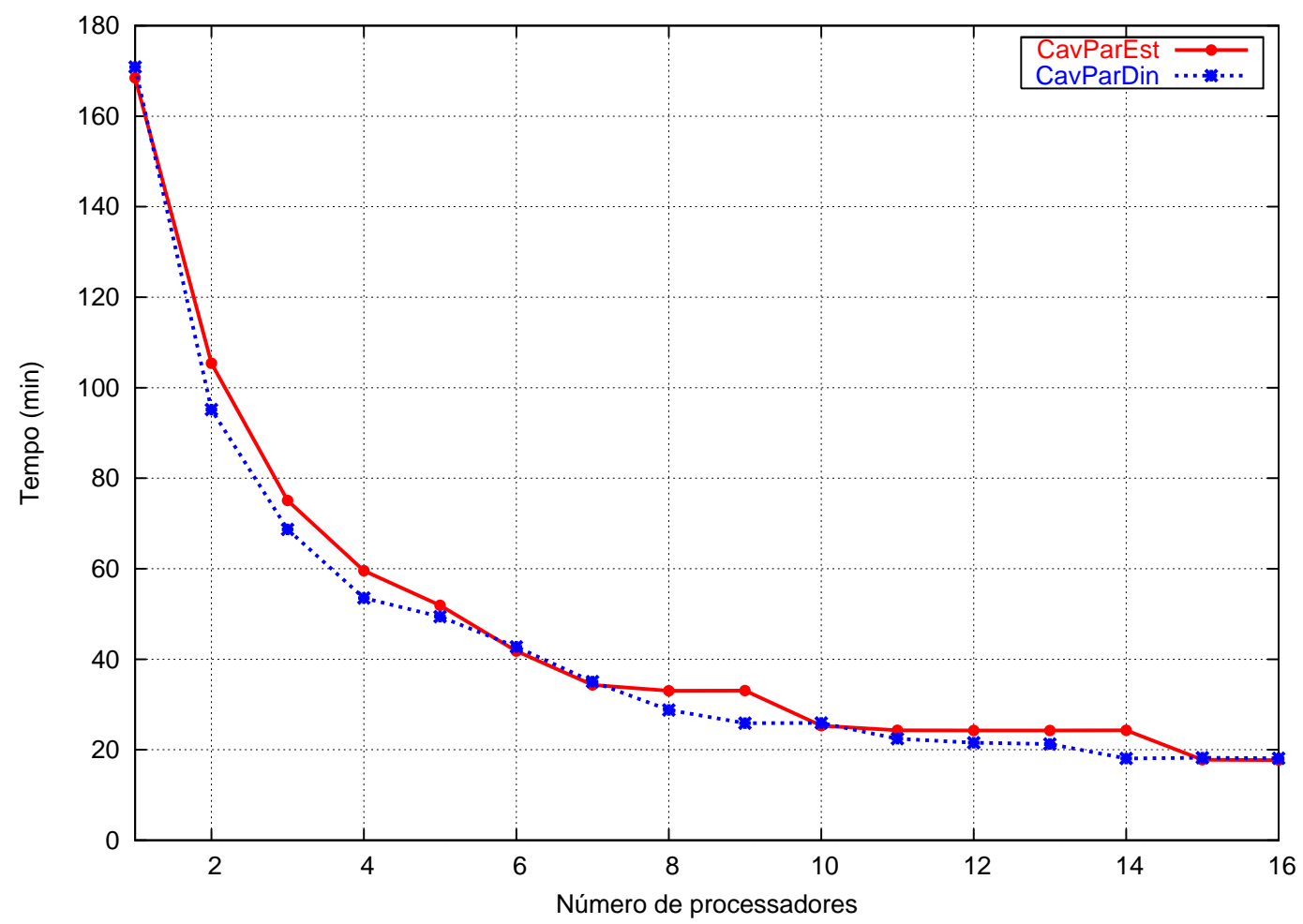

Figura 5.8: Gráfico mostrando o tempo de execução das aplicações paralelas em um cluster balanceado. Tabuleiro solucionado de $5 \times 6$.

Na figura 5.9, ainda se nota a existência de patamares na curva do CavParEst. O motivo é o mesmo descrito na subseção anterior. Por exemplo, entre $P=10$ e $P=14$, o maior número de casas que um processador pode receber é 3 e isso é o limitante no tempo de execução total da aplicação CavParEst. O mesmo não acontece com o CavParDin porque ele consegue distribuir melhor a carga entre os processadores e, com isso, obter aumento no speedup quando se acrescenta mais processadores. 


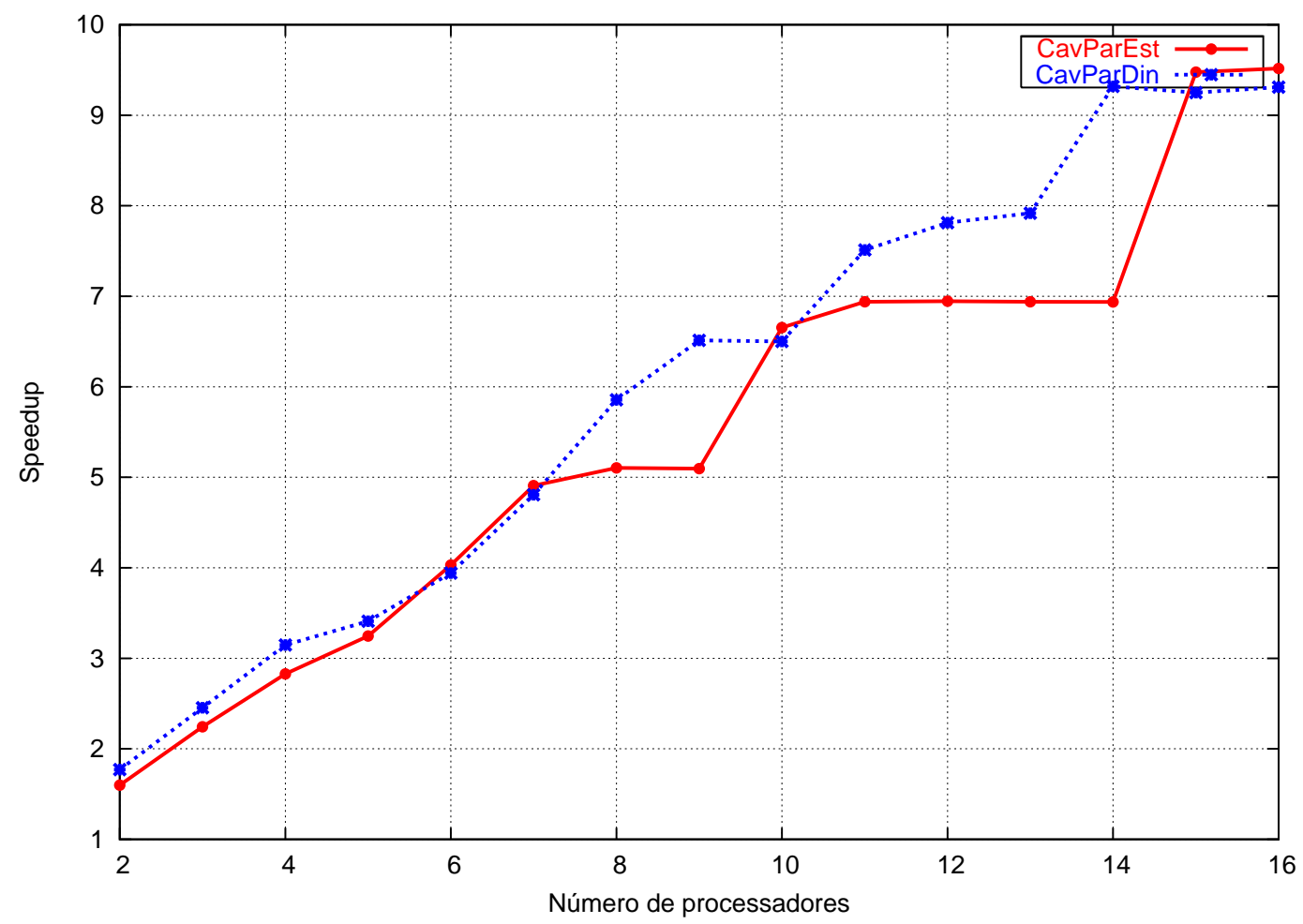

Figura 5.9: Gráfico em que é mostrado o speedup das aplicações paralelas em um cluster balanceado. Tabuleiro solucionado de $5 \times 6$.

\subsection{Resumo do capítulo}

Este capítulo teve a finalidade de descrever como foi testado o sistema de monitoramento de cargas e de relatar os resultados obtidos discutindo-os minuciosamente.

Para testar o sistema de monitoramento, foram desenvolvidas três aplicações: CavSeq, solução seqüencial, CavParEst, solução paralela que usa compartilhamento estático de cargas, CavParDin, solução paralela que usa compartilhamento dinâmico de cargas; todas para resolver o problema do passeio do cavalo em um tabuleiro de $M \times N$. Esse problema foi escolhido devido ao seu alto custo computacional, devido à facilidade de paralelização e por ter unidades de tarefa de fácil redistribuição.

Nenhuma das aplicações utiliza métodos sofisticados de resolução já que o intuito era só de teste e não de achar a melhor solução. O CavParDin, embora não use nenhum 
método aperfeiçoado para encontrar as soluções para o problema do passeio do cavalo, utiliza um algoritmo de distribuição sofisticada de cargas que é global, dinâmico, distribuído, cooperativo, não-adaptativo e iniciado pelo destinatário, enquanto que CavParEst utiliza um algoritmo simples global e estático. Aqui, procurou-se desenvolver as aplicações paralelas empregando os conceitos discutidos no capítulo 3.

A partir dos resultados, conclui-se que o algoritmo utilizado no CavParDin foi mais eficiente do que o CavParEst na maioria dos casos analisados. Essa conclusão se tornou mais evidente quando foi realizado o teste com o cluster desbalanceado, ajudando a elucidar a idéia inicial de desenvolver um sistema de monitoramento de cargas para sistemas distribuídos multi-usuários cujos nós possuam poderes computacionais diferentes como NOWs ou Grids computacionais. Outra conclusão importante foi a sobrecarga imposta pelo algoritmo de compartilhamento dinâmico de cargas ser baixa que por sua vez implica também ser baixa a sobrecarga imposta pelo sistema de monitoramento de cargas desenvolvido neste trabalho de mestrado. 


\section{CAPÍTULO \\ 6 \\ Conclusões e Trabalhos Futuros}

\subsection{Conclusões}

A proposta deste trabalho nasceu com a preocupação de desenvolver ferramentas que auxiliassem o programador a criar aplicações paralelas com mais facilidade, pois, como foi exposto no capítulo 2, a programação paralela é muito mais difícil do que a seqüencial. A questão abordada neste trabalho foi o balanceamento de cargas, visto que, além de limitar o desempenho, é uma das partes mais difíceis da programação paralela.

Outra motivação para este trabalho foi a pouca preocupação das ferramentas e das linguagens paralelas existentes com o balanceamento de cargas, fazendo com que o programador tenha que se preocupar com isso no desenvolvimento de aplicações paralelas. Como a construção de um sistema de balanceamento de cargas é uma tarefa muito custosa e demorada para um trabalho de mestrado, foi desenvolvido apenas a parte que monitora a carga de um sistema distribuído.

O intuito de construir um sistema de monitoramento de cargas foi de facilitar a programação de aplicações paralelas, tendo em vista a proposta inicial deste trabalho. Outra preocupação deste trabalho foi garantir que ele fosse portátil, visto que um dos objetivos desse sistema foi de ser voltado aos sistemas distribuídos multi-usuários heterogêneos como NOWs e Grids computacionais. A razão de suportar Grids computacionais foi que tais sistemas estão se tornando muito promissores atualmente, pois são sistemas com 
muitos recursos computacionais e alguns não só de uso privado.

A garantia de ser portátil pôde ser obtida através do uso de Java. Esse foi um dos motivos pela escolha dessa linguagem de programação assim como a facilidade de programação e a existência na própria linguagem de um padrão de comunicação, o RMI. Com relação ao Java, pode-se concluir que é uma das linguagens mais promissoras atualmente não só na programação paralela mas também na seqüencial. Além disso, Java é uma linguagem de boa aceitação entre os programadores e possui algumas facilidades intrínsecas à linguagem, como threads e RMI, que facilitam a programação paralela.

Além de serem portáteis, as aplicações paralelas que utilizarem o sistema de monitoramento de cargas terão sua programação facilitada graças à orientação ao objeto. A ferramenta de monitoramento de cargas fornece ao programador uma interface que pode ser facilmente expandida (inclusão de novos tipos de medidas, criação de aplicações paralelas que utilizem esta ferramenta, etc). Além disso, utilizar um objeto para representar o índice de carga e não só um número torna possível transmitir mais informação a respeito do computador que está sendo analisado. Assim, um único objeto pode conter informações sobre vários tipos de carga, por exemplo. Dados úteis que esse tipo de objeto deve conter são informações como: tipo de CPU, freqüência de operação, capacidade total da memória física, tipo de memória física, interface de rede, enfim algumas informações essenciais para determinar o poder computacional de um certo nó.

Com relação ao uso de um cluster de computadores do tipo Beowulf, embora não heterogêneo como os sistemas distribuídos para os quais o sistema de monitoramento de cargas foi proposto, ele permitiu um bom ambiente para desenvolvimento e teste, inclusive proporcionando bons resultados. No entanto, realmente teria sido melhor desenvolver e testar o sistema de monitoramento de cargas em um outros sistemas distribuídos, o que não foi possível pela falta de tempo.

Os resultados apresentados no capítulo 5 mostram que o sistema de compartilhamento dinâmico de cargas desenvolvido para testar o sistema de monitoramento foi melhor do que o sistema de compartilhamento estático na maioria dos casos testados. Isso não só demonstra que o sistema de compartilhamento dinâmico de cargas foi eficiente como 
também comprova a afirmação de que mesmo em sistemas distribuídos cujos nós sejam iguais, o balanceamento de cargas dinâmico é melhor do que o estático [28]. Além disso, conclui-se, a partir desses resultados, que o sistema de monitoramento de cargas impõe pouca sobrecarga no sistema distribuído. Este é um dos resultados mais importantes deste trabalho, por satisfazer um dos maiores objetivos desse sistema.

Enfim, a ferramenta criada neste trabalho constitui uma iniciativa para o desenvolvimento de um sistema de balanceamento de cargas em Grids computacionais. Além de fornecer a carga dos nós de um sistema distribuído às aplicações paralelas, ou a um sistema de balanceamento de cargas, a ferramenta desenvolvida também pode ser usada para gerenciamento de um computador paralelo. Desta maneira, o administrador de um sistema distribuído pode saber como os recursos computacionais de seu sistema estão sendo usados.

\subsection{Trabalhos Futuros}

Embora o sistema de monitoramento de cargas tenha se mostrado eficiente, ele ficou bastante limitado a computadores pessoais com Linux como sistema operacional. Um dos próximos passos seria implementar as medidas de carga de CPU, de memória e de rede para outras arquiteturas e para outros sistemas operacionais de maneira a permitir maior flexibilidade na sua utilização e assim garantir que ele seja portátil. Com isso, já seria possível testá-lo em Grids computacionais, por exemplo.

Ademais, também seria útil implementar novas medidas de carga, como, por exemplo, uso do disco rígido e tamanho da fila de processos. Isso tornaria o sistema de monitoramento mais versátil, deixando mais opções para o programador de aplicações paralelas escolher as que melhor resolver o seu problema.

Uma continuação possível para este trabalho seria desenvolver um sistema de compartilhamento de cargas que utilizasse o sistema de monitoramento. O sistema de compartilhamento seria uma ferramenta que englobaria uma interface de programação, de maneira a facilitar a tarefa de inserção de códigos de distribuição de cargas em aplicações para- 
lelas, e um distribuidor de cargas (um ambiente de tempo de execução). O distribuidor utilizaria o sistema de monitoramento para saber como os recursos do sistema distribuído estão sendo usados e realizaria o rebalanceamento de cargas. 


\section{Referências Bibliográficas}

[1] A. S. Tanenbaum. Organização Estruturada de Computadores. Livros Técnicos e Científicos, 3rd edition, 1999.

[2] G. Seshadri. Fundamentals of RMI. http://java.sun.com/developer/onlineTraining/rmi/RMI.html, 2000.

[3] Wikipedia, the free encyclopedia, http://www.wikipedia.org.

[4] D. E. Culler, J.P. Singh, and A. Gupta. Parallel Computer and Architecture: A Hardware/Software Approach. Morgan-Kaufman, 1998.

[5] Jack J. Dongarra, Hans W. Meuer, and Erich Strohmaier. TOP500 supercomputer sites, 22nd edition, November 2003.

[6] T. Sterling, D. Savarese, D. J. Becker, J. E. Dorband, U. A. Ranawake, and C. V. Packer. BEOWULF: A parallel workstation for scientific computation. In Proceedings of the 24th International Conference on Parallel Processing, pages I:11-14, Oconomowoc, WI, 1995.

[7] D. B. Skillicorn. Motivating computational grids. Technical report, Queen's University, 2001.

[8] M. J. Flynn. Some computer organization and their effectiveness. IEEE Transactions on Computers, 21:948-960, 1972.

[9] The Earth Simulator Center, http://www.es.jamstec.go.jp. 
[10] M. Livny and M. Melman. Load Balancing in Homogeneous Broadcast Distributed Systems. In ACM Computer Network Performance Symp., pages 47-55, 1982.

[11] I. Foster. Designing and Building Parallel Programs. Addison Wesley, 1995.

[12] MPI Forum. The Message Passing Interface Standard, 1995. http: //www . mpi-forum. org.

[13] D. Towsley T. Wagner. Getting Started With POSIX Threads,

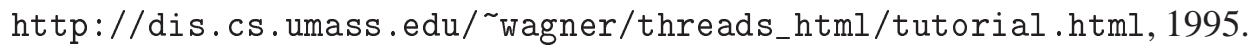

[14] D. R. Butenhof. Programming with POSIX Threads. Addison-Wesley, 1997.

[15] M. J. Wolf. High Performance Compilers for Parallel Computing. Addison-Wesley, 1995.

[16] The Stanford SUIF Compiler Group, http://suif.stanford.edu.

[17] PARADIGM: A Parallelizing Compiler for Distributed Memory Message-Passing Multicomputers, http://www.ece.nwu.edu/cpdc/paradigm/paradigm.html.

[18] Haskell, A Purely Functional Language, http://www.haskell.org.

[19] Sisal - A High Performance, Portable, Parallel Programming Language, http://www.llnl.gov/sisal.

[20] K. A. M. Ali. OR-parallel Execution of Prolog on a Multi-Sequential Machine. International Journal of Parallel Programming, 15(3), 1986.

[21] P. R. Serrarens and M.J. Plasmeijer. Explicit message passing for Concurrent Clean. In Proc. of Implementation of Functional Languages, 1998. 
[22] F. H. Carvalho, R. D. Lins, and R. M. F. Lima. Parallelizing MCP-Haskell for Evaluating The Haskell \# Parallel Programming Environment. In Proc. 13th Symp. on Computer Architecture and High Performance Computing, 2001.

[23] D. Skillicorn. Foundations of Parallel Programming. Cambridge Press, 1994.

[24] The Mentat Project, http://www.cs.virginia.edu/ mentat.

[25] L. Blackforda, J. Choi, A. Cleary, J. Demmel E. D’Azevedo, I. Dhillon, J. Dongarra, S. Hammarling, G. Henry, A. Petitet, K. Stanley, D. Walker, and R. C. Whaley. ScaLAPACK Users' Guide. SIAM, 1997.

[26] The Cactus Code Server, http://www. cactuscode.org.

[27] A. B. H. Ferreira. Novo Dicionário Aurélio da Língua Portuguesa. Nova Fronteira, 2nd edition, 2000.

[28] N. G. Shivaratri, P. Krueger, and M. Singhal. Load Distributing for Locally Distributed Systems. IEEE Computer, pages 33-44, December 1992.

[29] D. L. Eager, E. D. Lazowska, and J. Zahorjan. The limited performance benefits of migrating active processes for load sharing. SIGMETRICS, May 1988.

[30] D. Gupta and P. Beard. Load Sharing in Distributed Systems. In Proceedings of the National Workshop on Distributed Computing, January 1999.

[31] J. K. Ousterhout. Scheduling techniques for concurrent systems. In Proc. 3rd International Conference on Distributed Systems, IEEE, 1982.

[32] A. S. Tanenbaum. Modern Operating Systems. PHI, 1993.

[33] T. Kunz. The Influence of Different Workload Descriptions on a Heuristic Load Balancing Scheme. IEEE Trans. Software Eng., 17(7):725-730, 1991.

[34] R. F. Mello, M.S. Paiva, and L. C. Trevelin. Comparative Study of the ServerInitiated Lowest Algorithm using a Load Balancing Index Based on the Process 
Behavior for Heterogeneous Environment. Journal of Networks, Software Tools and Application, 2003.

[35] J. A. Stankovic. Stability and Distributed Scheduling Algorithms. IEEE Transactions on Software Engineering, 11(10), October 1985.

[36] T. L. Casavant and J. Khul. Effects of Response and Stability in Distributed Computing Systems. IEEE Transactions on Software Engineering, 14(11), November 1988.

[37] T. L. Casavant and J. Khul. A Taxonomy of Scheduling in General-Purpose Distributed Computing Systems. IEEE Transactions on Software Engineering, 14(2), February 1988.

[38] Y. T. Wang and R. J. T. Morris. Load Sharing in Distributed Systems. IEEE Transactions on Computers, pages 204-217, March 1985.

[39] K. M. Baumgartner and B. W. Wah. Computer scheduling algorithms - past, present, and future. Information Sciences, pages 319-345, September 1991.

[40] C. Xu and F. C. M. Lau. Load Balancing in Parallel Computers: Theory and Practice. Kluwer Academic Publishers, Boston, USA, 1997.

[41] D. G. Feitelson and L. Rudolph. Parallel job scheduling: Issues and approaches. In D. G. Feitelson and L. Rudolph, editors, Job Scheduling Strategies for Parallel Processing, pages 1-18. Springer-Verlag, 1995. Lect. Notes Comput. Sci. vol. 949.

[42] D. L. Eager, E. D. Lazowska, and J. Zahorjan. Adaptive load sharing in homogeneous distributed systems. IEEE Transactions on Software Engineering, 12(5), May 1986.

[43] D. L. Eager, E. D. Lazowska, and J. Zahorjan. A Comparison of Receiver-Initiated and Sender-Initiated Adaptive Load Sharing. Performance Evaluation, 6(1):53-68, March 1986. 
[44] P. Krueger and M. Livny. The Diverse Objectives of Distributed Scheduling Policies. In Seventh Int'l Conf. Distributed Computing Systems, pages 242-249, Los Alamitos, California, 1987. IEEE CS Press.

[45] N. G. Shivaratri and P. Krueger. Two Adaptive Location Policies for Global Scheduling. In 10th Int'l Conf. Distributed Computing Systems, pages 502-509, Los Alamitos, California, 1990. IEEE CS Press.

[46] UC Berkeley. SETI@home: Search for Extraterrestrial Intelligence at Home. http://setiathome.ssl. berkeley.edu/.

[47] D. Fanagan. Java in a Nutshell. O’Reilly, 3nd edition, May 1997.

[48] Bjarne Stroustrup. The C++ programming language. Addison-Wesley, 2nd edition, 1991.

[49] A. A. Cesta. Tutorial: A Linguagem de Programação Java. http://www.ic. unicamp.br/ cmrubira/aacesta/java/javatut.html, June 1996.

[50] A. S. Tanenbaum. Computer Networks. Prentice Hall PTR, 3rd edition, March 1996.

[51] N. Basnet, D. Pokharel, and S. Adhakari. STATE of CPU USAGE. Technical report, Department of Computer Science and Engineering, Kathmandu University, 2003.

[52] G. Gamow. One Two Three ... Infinity. Dover Books, New York, 1988. 